\title{
Sources of Gender Wage Gaps for Skilled Workers in Latin American Countries
}

\author{
Mauricio Tejada* $\quad$ Marcela Perticará ${ }^{*}$
}

November 2016

\begin{abstract}
In this paper, we estimate a search model of the labor market with participation decisions, search frictions, match-specific heterogeneity and taste discrimination (à la Becker) for skilled workers. The model is used to identify the impact of pure discrimination from the influence of other gender-specific labor market characteristics, such as unobserved productivity and differences in the labor market dynamics by gender. The model is estimated using data from eight Latin American countries. Our full flexible model accurately replicates the observed gender wage gaps in the data, not only on average but also at the top and bottom of the wage distribution. Wage gaps are larger at the top than at the bottom of the distribution. There is a large amount of heterogeneity in the sources of wage gaps (productivity, prejudice, dynamics of the labor markets) by country. Both productivity and prejudice are important sources of wage gaps. While on average, prejudice is not the main source of wage gaps for skilled workers in all countries, prejudice does generate higher wage gaps at the bottom of the distribution. At the top, productivity is the main force behind wage gaps.
\end{abstract}

JEL Code: C51, J7 and J64.

Keywords: Gender Discrimination, Search Models, Structural Estimation.

\section{Introduction}

Latin America is by far one of the regions with the lowest female labor force participation rates. Women are not only under-represented in the labor market, but also receive on average

*ILADES - Universidad Alberto Hurtado. Email: matejada@uahurtado.cl.

†ILADES - Universidad Alberto Hurtado. Email: mperticara@uahurtado.cl. 
much lower wages than men. According to the Global Gender Gap Report 2014 published by the World Economic Forum (GGGR thereafter), there has been good progress in closing educational, health and political empowerment gender gaps in most countries, but gender labor market gaps are still sizable and persistent in time. Consequently, the region fell to the fourth place in the ranking when labor market gaps were considered and to the fifth place (out of six) when labor force participation and wage gaps were used separately.

Labor economics literature that study wage gaps is vast (in general and for Latin American countries) and is, in general, based on the human capital theory. Many methodological approaches have been used in different studies to evaluate gender wage gaps ${ }^{1}$. One of the most popular procedures is the classic decomposition of Oaxaca (1973) and Blinder (1973), subsequently generalized by Oaxaca and Ransom (1994) and Neumark (1988). In this technique, wage differentials between men and women are decomposed ${ }^{2}$ into the portion explained by differences in human capital endowments (and other observables) and its returns. The portion of the predicted means not related to endowments is interpreted as discrimination ${ }^{3}$. This approach has several limitations.

First, focusing only on differences in the returns of observables might be a biased estimate of discrimination because unobservables, such as motivation, ability, or preferences are part of this residual ${ }^{4}$. Juhn et al. (1993) extended the methodology to include a third component -unobserved heterogeneity. Second, the Oaxaca-Blinder decomposition is only informative on the average wage gap. Several authors have proposed alternative methodologies that rely on non-parametric estimations (DiNardo et al., 1996) and resort to estimating a parametric model for the quantiles of the conditional distribution, afterwhich they propose different methodologies to recover the counter-factual distributions (Machado and Mata, 2005; Melly, 2005). Third, the distribution of men and women differs across jobs and sectors (segregation), which could be explained by discrimination, preferences or job availability at a given point in time (that is, labor market frictions). If dummy variables for sectors or occupations are added in the wage regression (to account for such differences), it would be equivalent to assume that there is no pre-emptive discrimination in accessing occupations and sectors, and it would be tempting to interpret (causally) that a higher fraction of the wage gap is related to these "observables". Moreover, as pointed out in Nopo (2008), when sector or occupational

\footnotetext{
${ }^{1}$ A good literature review on this topic can be found in Gunderson (2006), Altonji and Blank (1999), Blau (1998) and Blau and Kahn (2000), among others.

${ }^{2}$ In this literature, methods generally used are the Oaxaca and Blinder decomposition (parametric or non-parametric) or the Mincer wage equations.

${ }^{3}$ This procedure was extended by Juhu, Murphy and Pierce (1991) by taking into account the residual distribution.

${ }^{4}$ Atal et.al. (2009) estimate that the unexplained part of the wage gap is quite sizable for Latin American countries.
} 
dummy variables are included in the parametric wage model, it is assumed that the linear estimated coefficients are valid outside of the common (to both women and men) support of observables. Nopo (2008) proposes the use of matching techniques to overcome the critique related to focusing only on gaps over the mean wages, as well as to overcome the problem related to women and men having different support over observables.

In any case, all these approaches cannot be used to evaluate policies against discrimination because they do not take into account the effect of the policy on agents' (workers and employers) behavior. In other words, all these approaches can be useful for describing wage gaps but they cannot solve the fundamental identification problem, that is how to separate the impact of pure discrimination from other gender-specific labor market characteristics (such as unobserved productivity). Discrimination not only affects wage gaps but also participation and segregation gaps (at least, part of them $)^{5}$ since workers, when making labor market decisions, anticipate that in the labor market there are employers that discriminate against women (these are prejudiced employers). More recent literature that studies gender gaps and their determinants, uses a structural approach. A (stylized) theoretical model of the dynamics of the labor market is estimated using micro-data to evaluate and quantify the role of the productivity, preferences and discrimination on gender gaps. ${ }^{6}$ In this case, the decision making process of workers and employers and all the unobservables are explicitly modeled, after which the particular structure of the model is exploited to identify these components from the data. The strengths of this approach are twofold: first, the assessment of policies is less vulnerable to the Lucas critique and second, it allows for the construction of counterfactual scenarios (which are useful to decompose the gap in its sources). It is important to mention that this literature is still scarce in general and is non-existent (as far as is known) for the Latin American context.

Consequently, this paper uses this structural approach to study gender gaps in eight Latin American countries: Bolivia, Chile, Colombia, Ecuador, Mexico, Paraguay, Peru, and Uruguay. $^{7}$ In particular, a search model of the labor market (à la Diamond-MortensenPissarides) is estimated where participation decisions, search frictions, match-specific heterogeneity and taste discrimination (à la Becker) are allowed. This type of model is standard in the current state of the literature (Flabbi, 2010b). It is highly stylized (making it manageable) but rich enough in its dynamics to take into account the different potential sources of gender gaps.

\footnotetext{
${ }^{5}$ See Flabbi (2010a, 2010b) for a detailed explanation.

${ }^{6}$ See Flabbi (2010a) for a detailed literature review on this approach.

${ }^{7}$ Originally, the idea was to include Argentina and Brazil, but in both countries the unemployment duration data is recorded as discrete time-intervals which does not allow the use of these household data for the structural estimation.
} 
The labor market environment is simple and can be summarized as follows: the economy is populated by four types of agents -male and female workers, and prejudiced and unprejudiced employers. Prejudiced employers perceive a lower value of a labor relation when they hire a woman. The first decision is made by the workers. They decide whether to participate or not in the labor market according to how much they value activities different from those of the labor market. If they decide to participate, then they become unemployed agents searching for a job. Employers also search for workers trying to fill their vacancies. Once a worker and an employer meet, they realize the value of the labor relationship and the employer's type (this information is not available ex-ante). Also, they negotiate the wage and the labor contract is signed only if it is worth it for both parts. If it is not, they continue their search for the next potential match. If the labor relation is formed, the worker starts to work and receives the agreed wage. Of course, the relationship can be terminated at any time and both agents start their search again. On-the-job search is not allowed.

This paper follows the identification strategy developed by Flabbi (2010a) to estimate the proportion of prejudiced employers and the average discrimination intensity against women, while at the same time allowing for gender-specific productivity and gender-specific mobility parameters. The model is estimated only for skilled workers (workers with either technical or university degree) and for workers who are wage earners. ${ }^{8}$ With the estimated model, counterfactual scenarios are created to decompose the gap into three sources: productivity, search frictions and prejudice. Of course, this decomposition is performed by taking into account all the equilibrium effects (changes in the labor market environment induces individual agents to adjust their behavior).

The data requirements to apply this structural approach are not particularly binding. A cross-section database is used for each country with the following information: wages, hours worked, unemployment duration, gender, education level, and labor market status. These variables can typically be obtained from Household Surveys of many Latin American Countries.

The remainder of this paper is organized as follows. Section 2 describes the structural approach. Section 3 describes the data and provides background information on the countries analyzed. Section 4 presents and discusses the results of the estimation, while Section 5 presents our final remarks.

\footnotetext{
${ }^{8}$ Informality is a well known feature of Latin American labor markets and it is basically concentrated in low skilled workers (on average, around $40 \%$ of these workers are informal). Hence, this paper focus on high skilled workers, for whom formality rates are around $90 \%$, on average.
} 


\section{The Structural Approach}

For the structural analysis the strategy developed by Flabbi (2010a) is closely followed to identify explicit gender discrimination in the labor market in eight Latin American countries. This section presents the theoretical model used to decompose gender wage gaps in its sources and describes the structural estimation procedure. The methodological discussion in this paper is rather brief and informal. The theoretical model used is a search and matching model with bargaining and non participation decisions in line with Flabbi (2010b), in which gender discrimination is defined as explicit prejudice against women and modeled as taste (disutility) discrimination à la Becker (1971). The structural estimation is performed by maximum likelihood methods using data on participation, wages and unemployment durations and the identification conditions follow Flinn and Heckman (1982) for a standard search model and Flabbi (2010a) for the specific parametrization of the discrimination component of the model. Finally, counter-factual analysis is used to decompose observed gender wage gaps into gaps due to pure discrimination and gaps due to other (possibly unobserved) labor market gender characteristics.

\subsection{The Model}

As in Flabbi (2010b), it is assumed that time is continuous and that the economy is populated by infinitely lived risk neutral agents. Time is discounted at rate $\rho$. It is assumed that there are two type of agents -men and women-, which are indexed by $j=M, W$. At any point in time each agent can be employed, unemployed or non participating in the labor market. Non participating agents receive a flow utility $z$, which is a draw from the gender specific distribution $Q_{j}(z)$, from devoting their time to activities different from those of the labor market. Because agents differ in how much they value their time outside of the labor market, only those with low enough utility $z$ will be participating in it. Also, differences in the distribution of $z$ by gender captures the idea of differences in the likelihood of participating between men and women. ${ }^{9}$ Defining the value of non participation in the labor market for the agent type $j$ as $N P_{j}$, its flow value can be written as:

$$
\rho N P_{j}(z)=z \quad j=M, W
$$

In turn, while unemployed, agent $j$ receives a flow utility (or possibly disutility) $b_{j}$ and meets a potential employer at Poisson rate $\lambda_{j}$. Once the meeting occurs, a match-specific

\footnotetext{
${ }^{9}$ It is important to mention that the model shows dynamics between unemployment and employment states but not between participation and non participation. In particular, there are no transitions from employment or unemployment to non participation and the decision of participation is made once and forever.
} 
productivity $x$ is realized, which is a draw of the gender specific productivity distribution $G_{j}(x)$. Agents can meet one of the two types of employers presented in the economy, prejudiced $(P)$ or unprejudiced $(N)$. Prejudiced employers receive a disutility when meeting and hiring a woman and there is a proportion $p$ of this type of employers in the economy. For an unprejudiced employer, on the other hand, it is indifferent to hire a man or a woman and there is a proportion $1-p$ of this type of employers. ${ }^{10}$ Therefore, discrimination in the model takes the form of a taste-based explicit prejudice against women in line with Becker (1971) ideas. After meeting and the realization of the match specific productivity, employers and employees engage in wage bargaining and decide if the match is formed or not. The decision is made based on a reservation productivity; any match with a productivity greater than or equal to $x_{j P}^{*}$ if the employer is prejudiced and $x_{j N}^{*}$ if the employer is unprejudiced is acceptable for the employer and the employee. Let $U_{j}, V_{j P}(x)$ and $V_{j N}(x)$ be the unemployment value, the value of being employed by a prejudiced employer in a match with productivity $x$, and the value of being employed by a unprejudiced employer in a match with productivity $x$, respectively. Hence, the flow value of being unemployed for a type $j$ agent is:

$\rho U_{j}=b_{j}+\lambda_{j}\left\{p \int_{x_{j P}^{*}}\left(V_{j P}(x)-U_{j}\right) d G_{j}(x)+(1-p) \int_{x_{j N}^{*}}\left(V_{j N}(x)-U_{j}\right) d G_{j}(x)\right\} \quad j=M, W$

When the type $j$ worker is employed by a type $i$ employer, prejudiced $(P)$ or unprejudiced $(N)$, in a match with productivity $x$, he/she receives a flow income $w_{j i}(x)$. During the term of the match, involuntary separation shocks that lead to termination of the match arrive at gender specific Poisson rate $\eta_{j}$. In case of termination, the worker starts to look for a new job as unemployed and the dynamics of the model are reset. The flow value of being employed by type $i$ employer for a type $j$ worker in a match with productivity $x$ is, therefore,:

$$
\rho V_{j i}(x)=w_{j i}(x)+\eta_{j}\left(U_{j}-V_{j i}(x)\right) \quad j=M, W ; i=P, N
$$

On the other side of the market, the flow income received by an employer depends not only on the productivity but also on its own type and on the type of the employed who is matched. In particular, a prejudiced employer $(j=P)$ receives a flow income equal to the productivity $x$ if a man is filling the job, while he/she receives a flow income equal to $x-d$ if the the worker in the match is a woman. Thus the parameter $d$ represents the distaste of the prejudiced employer of hiring a woman (the explicit taste discrimination) and is a measure of discrimination intensity. Note that the larger the parameter $d$ the higher the match specific productivity $x$ should be to make the job effectively created. If the employer is unprejudiced

\footnotetext{
${ }^{10}$ The proportion of prejudiced employers is exogenous.
} 
$(i=N)$, he receives a flow income equal to the productivity $x$ regardless of the type of worker that is filling the job. In turn, the flow cost for a type $i$ employer of having a filled vacancy with a type $j$ worker with productivity $x$ is the wage rate $w_{i j}(x)$. Again, if an involuntary separation shock arrives, the match is terminated and the employer loses the value of the match and starts to search for a new worker to fill the job. Let $J_{i j}(x)$ be the value of a filled job for a type $i$ employer matched with a type $j$ worker with $x$, then the flow value of a filled job can be written as:

$$
\rho J_{j i}(x)=x-d I_{[j=W, i=P]}-w_{j i}(x)-\eta_{j} J_{j i}(x) \quad j=M, W ; i=P, N
$$

where $I_{[j=W, i=P]}$ is an indicator variable which is equal to 1 if $j=W$ and $i=P$ and zero otherwise. Equations (1) to (4) complete the description of the value functions that characterize the dynamics of the model. To close the model description, as is standard in the literature, the generalized axiomatic Nash bilateral bargaining outcome is used to determine wages. In particular, the wage rate solves the following problem:

$$
\begin{aligned}
w_{j i}(x) & =\underset{w}{\operatorname{argmax}}\left[V_{i j}(x)-U_{j}\right]^{\beta}\left[J_{i j}(x)\right]^{1-\beta} \\
& =\underset{w}{\operatorname{argmax}}\left[\frac{w_{j i}-\rho U_{j}}{\rho+\eta_{j}}\right]^{\beta}\left[\frac{x-d I_{[j=W, i=P]}-w_{j i}}{\rho+\eta_{j}}\right]^{1-\beta} \quad j=M, W ; i=P, N
\end{aligned}
$$

where $\beta$ is interpreted as the bargaining power of the worker. The solutions to the optimization problems in (5) split the total surplus, $S_{i j}(x)=V_{i j}(x)-U_{j}+J_{i j}(x)$, in fixed proportions at all points in time, that is: $V_{i j}(x)-U_{j}=\beta S_{i j}(x)$ and $J_{i j}(x)=(1-\beta) S_{i j}(x)$. Using these results, the wage equation is:

$$
w_{j i}(x)=\beta\left(x-d I_{[j=W, i=P]}\right)+(1-\beta) \rho U_{j} \quad j=M, W ; i=P, N
$$

The interpretation of wage equation (6) is standard: workers are paid a weighted average, according to the bargaining power, of the match productivity, discounting the disutility of hiring a woman for a prejudiced employer, and their outside option (that is, the unemployment flow value). Note that the presence of parameter $d$ in wage equation (6) shows the direct effect of the taste discrimination of wages.

The equilibrium of the model consists of a set of reservation values related to the decisions of participating given the realized utility $z$ and accepting a job given the realized productivity $x$. In the case of the former, the reservation value of not participating $z_{j}^{*}$ makes the agent indifferent between participating or not in the labor market, and therefore satisfies $N P_{j}\left(z_{j}^{*}\right)=$ 
$U_{j}$. Using equation (1) $z_{j}^{*}=\rho U_{j}$, which means that any agent with a value $z$ greater than $\rho U_{j}$ will not participate in the labor market. In the case of the latter, the reservation productivity $x_{j i}^{*}$ for $j=M, W$ and $i=P, N$ makes the agent $j$ indifferent between accepting a job with the employer $i$ or not, and therefore satisfies $U_{j}=V_{j i}\left(x_{j i}^{*}\right)$. Using equations (3) and (6), the reservation productivities for men are $x_{M P}^{*}=x_{M N}^{*}=\rho U_{M}$, while that for women, which depends on the type of employer, are $x_{W P}^{*}=\rho U_{W}+d$ and $x_{W N}^{*}=\rho U_{W}$. The reservation wages implied by these last reservation productivities are $w_{M P}^{*}=w_{M N}^{*}=\rho U_{M}$ and $w_{W P}^{*}=w_{W N}^{*}=\rho U_{W}$. Note that the second effect of the taste discrimination is a penalty on the requirements of hiring a woman (that is, prejudiced employers are pickier than non-prejudiced employers when hiring a woman). Finally, as shown in Flabbi (2010a) (Proposition 1), in equilibrium $\rho U_{W}<\rho U_{M}$ and therefore the outside option of women in the wage bargaining process is lower independently of the type of employer. This result, called the spillover effect, indicates that the presence of prejudiced employers worsens women's position even when facing a non-prejudiced employer. Additionally, in equilibrium, the presence of prejudiced employers makes women less likely to participate.

To conclude the description of the model, the combination of equations (2), (3), and (6) result in the Bellman equations for $\rho U_{M}$ and $\rho U_{W}$ :

$$
\begin{aligned}
\rho U_{j}= & b_{j}+\frac{\lambda_{j} \beta}{\rho+\eta_{j}}\left\{p \int_{\rho U_{j}+d I_{[j=W]}}\left(x-d I_{[j=W]}-\rho U_{j}\right) d G_{j}(x)\right. \\
& \left.+(1-p) \int_{\rho U_{j}}\left(x-\rho U_{j}\right) d_{j} G(x)\right\} \quad j=M, W
\end{aligned}
$$

where $I_{[j=W]}$ is an indicator variable which is equal to 1 if $j=W$ and zero otherwise. The solution of equation (7), the flow values $\rho U_{M}$ and $\rho U_{W}$, completely characterizes the equilibrium of the model (the reservation values in all states).

\subsection{Estimation and Identification}

The model described in the last section is estimated by maximum likelihood methods using cross-section information on the supply side of the labor market for each country. An advantage of the estimation procedure and the identification strategy of the sources of gender gaps using Flabbi (2010a) model is that the data requirements are not particularly stringent, a feature that is relevant when analyzing the case of most of Latin American countries. In particular, the data used includes labor market status of individuals, unemployment (outgoing) durations $t_{i}$ observed for unemployed agents and hourly wages $w_{i}$ observed for employer 
workers, by gender ${ }^{11}$. The model is estimated for skilled workers, who are defined as those who have completed tertiary education.

The likelihood function to be maximized, choosing the set of parameters $\Theta$, is:

$$
\begin{aligned}
& L(w, t, U, E, N P ; \Theta)=\prod_{j=M, W}\left\{\prod_{s=1}^{N_{j, N P}}\left[1-Q_{j}\left(\rho U_{j}\right)\right] \times \prod_{s=1}^{N_{j, U}}\left[h_{j} e^{-h_{j} t_{s}} \frac{\eta_{j}}{\eta_{j}+h_{j}} Q_{j}\left(\rho U_{j}\right)\right] \times(8)\right) \\
& \left.\prod_{s=1}^{N_{j, E}}\left[\left(\frac{\frac{(1-p)}{\beta} g_{j}\left(\frac{w_{s}-(1-\beta) \rho U_{j}}{\beta}\right)}{1-G_{j}\left(\rho U_{j}\right)}+\frac{\frac{p}{\beta} g_{j}\left(\frac{w_{s}+\beta d I_{[j=W]}-(1-\beta) \rho U_{j}}{\beta}\right)}{1-G_{j}\left(\rho U_{j}+d I_{[j=W]}\right)}\right) \frac{h_{j}}{\eta_{j}+h_{j}} Q_{j}\left(\rho U_{j}\right)\right]\right\}
\end{aligned}
$$

where

$$
h_{j}=\lambda_{j}\left[( 1 - p ) \left(1-G_{j}\left(\rho U_{j}\right)+p\left(1-G_{j}\left(\rho U_{j}+d I_{[j=W]}\right)\right]\right.\right.
$$

The first component, the contribution to the likelihood of the non participation information, is the probability of not participating in the labor market which, conditional on the model, is $\operatorname{Pr}\left[z>\rho U_{j}\right]=1-Q_{j}\left(\rho U_{j}\right)$. The second component, the contribution to the likelihood of duration data, is the density of durations $h_{j} e^{-h_{j} t_{s}}$ with $h_{j}$ being the hazard rate out of unemployment ${ }^{12}$, considering the fact that those durations are observed only for individuals who are participating and unemployed (the probabilities of participating and being unemployed, conditional on the model, are $\operatorname{Pr}[s \in N P]=Q_{j}\left(\rho U_{j}\right)$ and $\operatorname{Pr}[s \in U]=\frac{\eta_{j}}{\eta_{j}+h_{j}}$, respectively). The hazard rate out of unemployment, presented in equation (9), is the probability of termination of the unemployment state which can occur if the match productivity with any type of employer has a high enough productivity (greater than the employer specific reservation productivity). The last component, the contribution to the likelihood of wages data, is a mixture by type of employer of the observed wages distributions implied by the model, considering the fact that those wages are observed only for individuals who are participating and employed (the probability of being employed, conditional on the model, is $\left.\operatorname{Pr}[s \in E]=\frac{h_{j}}{\eta_{j}+h_{j}}\right)$. The construction of the density of observed wages is done first by mapping the productivity distribution $g_{j}(x)$ into the wage distribution through the wage equations in (6) and second by truncating the resulting wage distribution to the range of accepted wages (that is, all wages greater than the reservation wage). The resulting densities

\footnotetext{
${ }^{11} \mathrm{~A}$ description of the data is provided in section 3 .

${ }^{12}$ Note that in the specification of the likelihood, unemployment durations have a negative exponential distribution, which is a direct consequence of a constant hazard rate conditional on the model (that is, it does not show duration dependence).
} 
of accepted wages are:

$$
f_{j N}^{o}(w)=\frac{\frac{1}{\alpha} g_{j}\left(\frac{w-(1-\alpha) \rho U_{j}}{\alpha}\right)}{1-G_{j}\left(\rho U_{j}\right)}
$$

and

$$
f_{j P}^{o}(w)=\frac{\frac{p}{\alpha} g_{j}\left(\frac{w+\alpha d I_{[j=W]}-(1-\alpha) \rho U_{j}}{\alpha}\right)}{1-G_{j}\left(\rho U_{j}+d I_{[j=W]}\right)}
$$

for the unprejudiced and prejudiced employers, respectively. Finally, the parametric assumptions regarding the distribution of the two sources of heterogeneity in the model complete the description of the likelihood function. On one hand, it is assumed that the value of out of the labor market activities $z$ follows a negative exponential distribution, that is $Q_{j}(z)=1-e^{-\gamma_{j} z}$. On the other hand, for the match-specific productivity $x$ a log-normal distribution is assumed with a density function $g_{j}(x)=\frac{1}{\sigma_{j} x} \phi\left(\frac{\ln (x)-\mu_{j}}{\sigma_{j}}\right)$ where $\phi(\cdot)$ is the normal standard density function. Both distributions are invertible. Using all these parametric assumptions, the likelihood function in equation (8) is maximized choosing the following set of parameters:

$$
\Theta=\left\{\lambda_{M}, \lambda_{W}, \eta_{M}, \eta_{W}, \mu_{M}, \sigma_{M}, \mu_{W}, \sigma_{W}, p, d, \rho U_{M}, \rho U_{W}, \gamma_{M}, \gamma_{W}\right\}
$$

Following Flinn and Heckman (1982), the reservation wage can be estimated using the minimum observed wage in the sample of employed workers ${ }^{13}$, that is:

$$
\hat{w}_{j}^{*}=\rho \hat{U}_{j}=\min \left\{w_{i}^{o b s}\right\}_{i=1}^{N_{j, E}}
$$

As in Flabbi (2010a) 5\% of the lowest observations are dropped when estimating the reservation wage. Additionally, Flabbi (2010b) shows that the likelihood estimation of the parameter $\gamma_{j}$, under the assumption of a negative exponential distribution for $z$, is:

$$
\hat{\gamma}_{j}=\frac{\log \left(N_{j} / N_{j, N P}\right)}{\rho \hat{U}_{j}}
$$

and makes use only of the estimated reservation wages and the proportion of the population that does not participate in the labor market by gender. Given $\rho \hat{U}_{j}$ and $\hat{\gamma}_{j}$ for $J=M, W$, the concentrated likelihood in equation (8) can be estimated choosing only the following parameters:

$$
\Theta^{\prime}=\left\{\lambda_{M}, \lambda_{W}, \eta_{M}, \eta_{W}, \mu_{M}, \sigma_{M}, \mu_{W}, \sigma_{W}, p, d\right\}
$$

As discussed in detail in Flabbi (2010a), the rate at which workers and potential employers meet $\left(\lambda_{j}\right)$ is identified from the unemployment duration data (or the hazard rate out of

\footnotetext{
${ }^{13}$ In fact, Flinn and Heckman (1982) show that the minimum observed wage is a strongly consistent estimator of the reservation wage.
} 
unemployment), while both $\lambda_{j}$ and the steady state condition are necessary to identify the arrival rate of involuntary shocks ${ }^{14}$. In turn, the productivity distributions are identified from the observed wage distributions using the mapping from productivity to wages and the truncation point at the reservation productivity. The condition that allows the identification is the invertibility feature of the log-normal distribution, that is the original distribution can be recovered from a truncated distribution. The identification of the parameters $p$ and $d$ is possible by exploiting differences in the productivity distributions between men and women. The necessary condition to identify $p$ and $d$ on the top of the parameters of the productivity distributions is that those distributions have to belong to a location-scale family. The lognormal satisfies this condition again. Finally, as is usual in the literature that estimate structural search models with supply side data ${ }^{15}$, we do not attempt to identify the parameter $\alpha$-the bargaining power of workers in the Nash bargaining game ${ }^{16}$ - and instead set its value to 0.5 .

Six models are estimated and the best estimated model is used to perform the counterfactual experiments. In the first model, there are differences only in the parameters of the productivity distribution by gender and there is no prejudice $(d=p=0)$. The second model introduces prejudice but imposes homogeneity by gender in both the labor market dynamics and the productivity distributions. In the third model, there are differences in the productivity distributions by gender and the existence of prejudice. In model 4 , there is complete heterogeneity by gender in the parameters in both the labor market dynamics and the productivity distributions but there is no prejudice. In model 5 , differences in the dynamics of the labor market by gender and prejudiced are allowed while keeping the same wage distribution for men and women. Finally, model 6 has complete heterogeneity in all parameters and allows prejudice. Due to space considerations the estimation results discussed in the next section only show the estimates of the best model, but all the results are available by request.

\footnotetext{
${ }^{14}$ In steady state, the flows in and out of unemployment should be equal to maintaining the number of unemployed and employed workers constant.

${ }^{15}$ See Eckstein and van den Berg (2007) for a complete survey.

${ }^{16}$ Additionally, the parameters $\rho$ and $b$ are not separately identified because both affect the reservation values. To identify $b, \rho$ is set and the equilibrium condition and the estimates for the reservation wages are used. The values of $\rho$ for each country are borrowed from Lopez (2008).
} 


\section{Background and data}

\subsection{Gender Disparities in Latin America}

Most Latin American countries have grown considerably in the last 10 years (or so), due to the particularly positive cycle of the commodity prices in the world. However, they are still behind in reducing income inequality and other economic disparities, such as gender and racial gaps. Indeed, income inequality has been historically high and persistent in these countries (particularly in Brazil, Colombia, Mexico and Chile) making the region one of the most unequal regions worldwide (OECD, 2016). In addition, in the region gender wage gaps are quite high and ethnic wage differences are even greater than gender differences (Atal et.al., 2009).

The current state of the gender gaps in Latin American countries is well depicted in the Global Gender Gap Report 2014 published by the World Economic Forum (GGGR thereafter). This report presents gender gap indices for 142 countries. These indices quantify the magnitude of the disparities between men and women across four areas (health, education, economy and politics) and track their progress over time (Word Economic Forum, 2014). According to this report, there has been an important progress in closing educational, health, and political empowerment gender gaps in most countries. However, gender gaps still persist and are sizable in the labor market. As a consequence, the region rank fell to the fourth place when labor market gaps were considered and to the fifth place (out of six) when labor force participation and wage gaps were used separately as comparison measures.

Figures 1 to 4 illustrate, for the eight Latin American Countries, the magnitude of gender labor gaps in four dimensions: participation, wages, high skilled employment and top job gaps. All figures also show the same gap for three developed countries (the United States, Germany and Canada), as well as the rank position of each country in the $G G G R$ (reported in parenthesis).

Figure 1 shows the participation rate gap ${ }^{17}$. It is observed that, on average, female labor force participation (FLFP) rates in these Latin American countries are almost 30\% lower than that for men, with Bolivia being the country with the lowest gap (20\%). Moreover, developed economies are ranked in the top 50 based on the participation gaps, while in Latin America countries hold positions as low as 68 and as high as 118. Wage gaps (unconditional to observed characteristics) are shown in Figure $2^{18}$. Note that, on average, women earn $47 \%$ less than men: Chile and Colombia are the countries with the highest and the lowest gaps, respectively. The gaps, observed in wages, rank these Latin American countries among those

\footnotetext{
${ }^{17}$ This is the ratio between the participation rates of female and male workers.

${ }^{18}$ This is the ratio between the average wages of female and male workers.
} 
with greater gender disparities (these countries rank between 106 and 128 of 142 countries), clearly positioning them above the developed world.

Figure 3 shows that in this group of Latin American countries, the results are mixed in the case of gender gaps related to access to high skill jobs (professional and technical workers $)^{19}$. Indeed, in some countries, like Peru and Mexico, the employment rate for women in these types of jobs is more than $20 \%$ lower than that for men; while in other countries, like Uruguay, the gap is in favor of women. Also, it is worth mentioning that in the developed world, job segmentation by skill level is either close to zero or even in women's favor. Finally, Figure 4 shows employment rates in top jobs (managers, senior officials and legislators). The glass ceiling hypothesis is clearly observed in this group of countries because, with the exception of Colombia, the employment rate in these jobs is between 22 and $69 \%$ lower for women than for men. These results are more in line with those observed in the developed countries considered for comparison purposes (Canada, USA and Germany). To sum up, gaps in participation and wages in Latin American countries are high, while women appear to be segregated in low-skilled jobs.

There is a vast literature for Latin America that study gender wage disparity trying to assess whether wage gaps can be explained by observables and unobservables, using either the traditional Blinder-Oaxaca decomposition technique or more generalized approaches such as those suggested by Machado and Mata (2005) and Melly (2005) or more recently Nopo $(2008)^{20}$. But there are few papers ${ }^{21}$ that study wage gaps using harmonized data in the region. Two more recent papers, are Carrillo et al. (2014) and Nopo et al. (2010). Carrillo et al. (2014), following Firpo et al. (2009), use quantile regressions to decompose gender wage gaps in twelve countries, finding that a substantial unexplained gender wage gap, in particular, is in the extremes of the wage distribution. There is high heterogeneity in the sample. The magnitude of these gaps at the top and bottom of the wage distribution is highly correlated with GDP and income inequality. Nopo et al. (2010), using data from eighteen countries, finds that for the whole region men's wages are $10 \%$ higher than those of women, but if women were equal to men (in terms of observables), the wage gap would jump to $20 \%$. The authors find substantial cross-country heterogeneity both in the raw gaps and in the unexplained gender gaps. It is worth noting that the authors find that wage gaps are higher for self-employed workers, regardless of the conventional wisdom.

\footnotetext{
${ }^{19}$ This is the ratio between the proportion of female workers in a particular type of job and their male counterparts.

${ }^{20}$ Most papers use years of education, age, type of worker (salaried or non-salaried) and occupation as observables.

${ }^{21}$ Most studies are country-specific. See for example Arceo-Gómez and Campos-Vázquez (2014) for Mexico, Badel and Peña (2010) for Colombia, Borraz and Robano (2010)for Uruguay, among others. Nopo et al. (2010) provides a comprehensive review.
} 


\subsection{Data}

This paper uses data from household surveys and employment surveys from eight LatinAmerican countries (see Table 1 for a description of the data). The data have been homogenized in order to recover information on wages, gender, (ongoing) unemployment duration, age, education and employment status. All the data sets are representative at the national level. The analysis will be focused on wage earners between 25 and 55 years old. Data on wages is obtained from the individuals primary occupation only, and hourly wages are estimated using reported working hours for this occupation and expressed in constant PPP US dollars of December 2013. The reasons for using only workers who are wage earners are twofold. First, self reported data on wages for self employed workers is typically very noisy and measured with errors and second, and more importantly, it is difficult to rationalize the idea of employer discrimination in a self-employment context. Table 2 shows that in seven out of eight countries in our sample self-employed workers represent, on average, less than $20 \%$ of the skilled employment. The exception is Colombia, where this figure is $30 \%$.

Note that the theoretical model used for the structural estimation does not explicitly model the informal sector and therefore it does not differentiate between formal and informal wage earners in the data ${ }^{22}$. In addition, it is not appealing to leave out informal workers from our analysis since segmentation of labor markets is likely to be incomplete between these two sectors. .

Tables 3 and 4 present descriptive statistics for unemployment durations and hourly wages by gender. There is a huge cross-country heterogeneity in unemployment durations. Countries like Chile, Mexico and Peru, are those with the lowest (ongoing) unemployment durations, while Uruguay, Bolivia and Paraguay have the highest. Unemployment durations are higher for women, except in Mexico and Peru, where this relationship is reversed. The highest gaps in unemployment durations by gender is found in Bolivia and Paraguay, while the smallest gaps are found in Chile, Colombia and Uruguay.

The highest gender wage gap is found in Chile (followed by Ecuador), while the lowest gaps are found in Uruguay, Bolivia.and Mexico. In all the countries, except Colombia, men's wage distributions show a higher relative dispersion (measured using the coefficient of variation) than women's. The gap by gender is relatively dispersed between $5 \%$ for Chile and $20 \%$ for Bolivia and Ecuador. The country with the highest relative dispersion for both women and men is Chile while the country with the lowest is Ecuador.

Figures 5 to 12 show non-parametric estimates of the accepted wage distributions by country, skill level and gender. The observed gender differences in those distributions are

\footnotetext{
${ }^{22}$ We are currently working on an extension of Flabbi (2010a) model to incorporate both formal and informal jobs.
} 
explained by the information being used to identify the productivity distributions and the discrimination parameters, along with the structure of the model.

Nopo et al. (2010) use data from the previous decade (around 2005) and include younger individuals in their sample. Hence, the results of this paper are not comparable to theirs. But it is interesting to estimate similar measures as the ones reported by these authors, in order to compare our structural estimates with the ones we could obtain otherwise. Table

5 presents the decomposition of wage gaps following Nopo (2008) for wage earners using three different sets of observables. The higher unexplained wage gaps between men and women, after controlling for education and age, are found in Chile and Ecuador, while the smallest gap is found in Mexico. In all countries, controlling for formal and informal jobs or occupation does not substantially change this estimate. But the unexplained gap drops in five out of eight countries when controling for employment sector. Sector wage differences seem to explain a relatively high portion of wage gaps in Chile, Colombia, Paraguay, Peru and Uruguay.

\section{Results}

\subsection{Estimation Results}

Table 6 presents the estimated parameters for skilled workers. For all countries, except Colombia, the model with complete heterogeneity in the parameter of the labor market by gender and with the presence of prejudice is supported by the data. For Colombia the best model does not include prejudice. In terms of the estimated parameters, the main findings are five-fold. First, rows one and two of table 6 show the estimates of the Poisson rate at which workers meet potential employers (or the rate at which job offers arrive). From the results, it can be noted that there is considerable heterogeneity among the Latin American countries in terms of how often job offers arrive and that no pattern can be found by gender. Job offers arrive between 1 to 7.4 months on average in the case of men, being Peru and Uruguay the countries with the highest and the lowest frequency of job offer arrivals, respectively. In the case of women, job offers arrive between 0.94 and 11.5 months on average, with Peru and Bolivia being the extreme cases. In two countries, Bolivia and Paraguay, job offers arrive much slower for women than for men; in three of them (Colombia, Ecuador and Uruguay), frequencies (although favorable for men) show a much smaller gap. In the remaining three, job offers arrive faster for women than for men.

Second, rows three and four of table 6 show the estimates of the Poisson rate at which involuntary separations shocks arrive and they convey information on the average duration 
of a job. As in the case of the arrival rate of jobs, there is a considerable heterogeneity on the average duration of jobs among the Latin American countries. Bolivia, Ecuador, Paraguay and Uruguay are the countries for which jobs last longer and this holds regardless of gender. In these countries, jobs last between 11 and 20 years and between 8 and 34 years for men and women, respectively. On the other extreme, in Colombia, Mexico and Peru, jobs last at most 3 years on average. In two countries, Bolivia and Paraguay, job duration for women is almost twice the job duration for men. On the contrary, in Colombia and Peru, job durations for men almost double job durations for women. In Chile, Mexico and Uruguay gender differences are smaller.

Third, rows six to eight of table 6 show the location and the scale parameters of the productivity distributions by gender. Given the log-normality assumption, the average productivity implied in those estimates are shown by gender in the first two rows of table $7^{23}$. In five out of eight countries, the average productivity is higher for men than fit is or women, where Chile and Ecuador are the countries with a greater difference $(36 \%$ and $20 \%$ respectively); in Colombia, Paraguay and Peru, the productivity gap between men and women (although favorable for men) are smaller (around 4 to $7 \%$ ). In the remaining three, women are more productive by men, by 4 to $6 \%$ in Bolivia and Mexico, but by almost $10 \%$ in Uruguay.

Fourth, rows nine and ten show the estimates of the intensity of discrimination and the proportion of prejudiced employers. It is important to mention that the intensity of discrimination is not directly comparable across countries and skill levels because the workers have different productivities in both dimensions. In order to compare the results, a relative measure of intensity of discrimination is defined as the ratio between the parameter $d$ and the average productivity of men $E[x \mid M]$. Figure 13 shows this measure of relative intensity and the proportion of prejudiced employers, graphically summarizing (comparable) information related to rows nine and ten of table 6 . It is important to make two comments regarding figure 13. First, the intensity of discrimination ranges between 10 and $44 \%$ of the average productivity of men. The lowest intensity of discrimination is found in Ecuador, while the highest is found in Mexico. The intensity of discrimination is around 30\% in Uruguay and Bolivia, and around 15\% in Paraguay and Peru. Furthermore, the intensity of discrimination is $22 \%$ in the country that shows the highest wage gap between men and women -Chile. Second, there is no variation in the proportion of prejudiced employers; for all the countries this proportion is around $50 \%$. The only exception is Colombia, where the existence of prejudiced employers for skilled workers is rejected.

Finally, rows eleven and twelve of tables 8 and 9 show the estimates of the reservation

\footnotetext{
${ }^{23}$ Recall that if $x \sim \operatorname{LogNormal}(\mu, \sigma)$ then $E[x]=e^{\mu+0.5 \sigma^{2}}$ and $V[x]=\left(e^{\sigma^{2}}-1\right) e^{2 \mu+\sigma^{2}}$.
} 
wages by gender. In all the countries, except Bolivia, Mexico and Paraguay the reservation wage for men tends to be higher than the reservation wage for women (between 8 to 20\%), which implies that employers are pickier when hiring a woman. The higher difference is found in Uruguay and Colombia, followed by Peru, Ecuador and Chile. In Bolivia and Paraguay, reservation wages for women are marginally higher than for men, while in Mexico reservation wages show almost no differences by gender.

Regarding the goodness of fit of the model, table 7 compares the predictions of the model for the average wage, the unemployment rate, and the unemployment duration and their sample data counterparts. It is notorious that the overall fit of the model is very good for all countries.

\subsection{Sources of Gender Wage and Participation Gaps}

In order to isolate the sources of gender wage gaps a set of counter-factual experiments is performed. In each experiment the ratio of wages between women and men is calculated for the average and for the top and bottom $25 \%$ of the wage distribution. Also, all the equilibrium effects are considered in the computations. The first experiment (called Productivity) analyzes how important productivity differences are by allowing differences only in the parameters that characterize the productivity distribution $\mu$ and $\sigma$ (the point estimates for men and women are used) and by setting all the remaining parameters at the point estimates for men and $p=d=0$. The second experiment (called Prejudice) analyzes the role of the discrimination intensity and the proportion of prejudiced employers in gender gaps. In this experiment all parameters different from $d$ and $p$ are set at the point estimates for men. The last experiment (called Transitions) analyzes the role of differences in the labor market dynamics by gender. In this case there are differences in the arrival rates of jobs and involuntary separations, parameters $\lambda$ and $\eta$, and as before the remaining parameters are set at the point estimates for men and $p=d=0$. The wage gap that each experiment generates ${ }^{24}$ is presented in the first three rows corresponding to each country in Table 8. Column (1) presents the mean wage gap, while columns (2) and (3) present wage gaps at the bottom and top (25\%) of the wage distribution. Additionally, row 5 presents the gaps generated by the model, with all the parameters set at their point estimates (row labeled All Parameters in the table), and row 6 shows the wage gap observed in the data (row labelled Data in the table). Column (4) presents gender ratios in participation rates for the three experiments.

Two general comments can be made from columns (1) to (3) in this table. First, the model with all estimated parameters adequately replicates the observed gender wage and

\footnotetext{
${ }^{24}$ Recall that the wage gap is the wages of women as a fraction of that of men. Therefore a wage gap of 0.89 means that the model predicts that women on average earn $11 \%$ less than men.
} 
participation gaps. In the particular case of wages, this is observed both in the average and at the top and bottom of the wages distribution. Second, a considerable heterogeneity is observed in the sources of the wage gaps by country.

In the case of Bolivia, women earn $6 \%$ less than men and the two main sources of this gap are prejudice and transition dynamics. If everything else were equal between men and women, women would earn 14 and $13 \%$ less than men, respectively. It is particularlyimportant to observe the bottom of the wage distribution where prejudice and dynamics generate a gap of 30 and $35 \%$. At the top of the wage distribution, all three sources of wage gaps generate a similar gap of around $7 \%$. Productivity favors women both on the average and at the bottom, generating higher wages for women than form men. At the top, however, productivity generates gaps of around $7 \%$.

Chile and Ecuador are the two countries with the highest wage gaps in the sample, $30 \%$ and $20 \%$ respectively. In Chile, these gaps against women are explained by differences in productivity (35\% on the average but almost $42 \%$ at the bottom of the distribution) and prejudice ( $12 \%$ on average but almost $36 \%$ at the bottom). At the top of the distribution, prejudice plays a smaller role, but productivity still generates a big gap (36\%). Transitions favor women both at the average and at the bottom and top of the distribution, generating favorable wage gaps of around 5\%,17\% and 3\%, respectively. In Ecuador, the gender wage gap is explained mostly by differences in productivity (23\%), while prejudice employers and labor market dynamics generate gaps of around 5\%. Productivity exacerbates the gap at the top of the distribution, while the other two sources generate a higher gap at the bottom.

In Colombia, prejudice does not play any role for skilled women. Predicted wage gaps are around $10 \%$ on average and $8 \%$ at the bottom and top of the distribution. On average, both productivity and transitions have a similar role (the first one generating a gap of 12 and $15 \%$ respectively). At the bottom of the distribution, labor market transitions play a larger role, generating a gap of almost $40 \%$.

Mexico has a similar wage gap as Bolivia of around 6\%. Prejudice plays an important role, generating a gap of almost $23 \%$ on average and a gap as high as $60 \%$ on the bottom part of the distribution. Both Productivity and labor dynamics favor women, reversing wage gaps both at the average and at the bottom. At the top, the role of productivity is reversed, while the role of labor market dynamic, remains favorable towards women.

In the case of Paraguay and Peru, wages for skilled women are 12 and 10\%, respectively, lower than those for men. On average, the main driving force in both countries is labor dynamics (with a gap of 15 and $13 \%$, respectively), closely followed by productivity (13 and $11 \%$, respectively) and by prejudice ( 8 and 10\%, respectively). At the bottom, both prejudice and labor dynamics generate a wider gap, of almost 20 and 35\% respectively in Paraguay 
and 25 and $33 \%$ in Peru. On the contrary, at the top, productivity is again the main source (19\% in Paraguay and $13 \%$ in Peru).

Finally, Uruguay is the country with the lowest gender wage gap in our sample, $4.7 \%$. This gap is mainly explained by prejudice. The gap generated due to prejudice is $14 \%$ on average, but almost 31.5\% at the bottom and $7 \%$ at the top. Productivity favor women with a gap of $13 \%$ on average and almost $40 \%$ on the bottom, while neutralizing wage differences at the top.

As can be noted, there is a lot of heterogeneity in the wage gap levels by country, and by the importance of the different sources: productivity, prejudice and labor market dynamics. Both productivity and prejudice are important sources of wage gaps. In countries such as Chile, Colombia, Ecuador, Peru and Paraguay, differences in productivity between men and women generate wage gaps that ranges from $35 \%$ in Chile to $7 \%$ in Peru, with higher gaps for the top $25 \%$ in all these countries. Particulrly in Chile the highest gap due to this source is at the bottom of the distribution (42\%). In one country -Uruguay- productivity has an equalizing role throughout the whole wage distribution. In Bolivia and Mexico, productivity also favors women on average but mostly on the bottom of the distribution. Prejudice is also an important source of gender wage gaps among skilled workers. In all countries, except Colombia, prejudice plays an important role; wage gaps under a prejudiced scenario ranges from $5 \%$ in Ecuador to $23 \%$ in Mexico on average, but increases to 20 and $60 \%$ at the bottom $25 \%$, and are much smaller at the top of wages distribution. That is, prejudice creates smaller gaps for high-wage earners. Labor market dynamics favor skilled women in only two out of eight countries (Chile and Mexico ${ }^{25}$, play a minor role in Uruguay and hurt women in the the remaining five countries. Once again larger effects are found a the bottom of the distribution, with negative effects in the order of $30 \%$ for four countries (Bolivia, Colombia, Paraguay and Peru) and positive effects in Chile and Mexico (-16 and $-30 \%$ respectively). It is worth noting that, with the exception of Bolivia, Mexico and Uruguay, productivity is by far the most important source of wage gaps against women at the top of the distribution.

\subsection{Policy simulations: hiring subsidy and equal-pay policies}

With the model it is possible to analyze the potential impact of two different policies: a hiring subsidy ( $10 \%$ of the estimated $d$ ) and an equal-pay policy. In the first case, a subsidy is offered to prejudiced employers. In the second, a law is passed, forcing all employers to pay equal wages to both women and men. In both cases, we measure the impact of the policy on workers' welfare, and other labor market outcomes such as wages, unemployment durations,

\footnotetext{
${ }^{25}$ Flabbi (2010b) also finds a similar result for skilled women in the US.
} 
labor market participation, among others. Results of such simulations are presented in Table 9. Panel A, labeled "Base Model" shows the base scenario, without policy. The first three rows show welfare measures for both women and men and for the whole sample. The last five rows show gaps in reservation wages, average wages, unemployment duration, unemployment and participation rates. Note that all gaps are expressed as ratios men/women. As it was expected, welfare is smaller for women than for men. Peru, Colombia and Chile are the countries with the highest welfare gaps between men and women. Panel B, labeled Affirmative Action Policy, shows the scenario in which prejudiced employers are lured into hiring women by offering to cover $10 \%$ of $\mathrm{d}$ (discrimination intensity). It can be seen that welfare fall for men (at most $4 \%$ in Mexico), and goes up for women (from 1\% in Paraguay to $8 \%$ in Peru). Welfare is reduced for men, as they now receive a smaller after-tax salary. In terms of labor market outcomes, the policy reduces the wage gap the most in Mexico (6 p.p.), followed by Bolivia, Chile and Uruguay (4 p.p.) and finally Ecuador, Paraguay and Peru (2 p.p.). Participation rate gaps also drop; the maximum impact is found in Mexico, where the ratio goes from 1.47 in the base scenario, to 1.30 under the affirmative action policy (the drop is 17 p.p.). The smallest change in participation rates is found in Ecuador and Paraguay (2 p.p.), but in any case all the other countries obtain small gains (at most gains of 5 p.p.). No meaningful changes are found in unemployment duration or unemployment rates.

Panel C, labeled Equal Pay Policy, shows a scenario in which all employers are forced to pay both women and men a wage equal to the average productivity of both workers. The average wage, is then defined as the weighted average of wages of women and men in the base scenario. It is worth noticing that as this policy neutralizes wage gaps for men and women of equal productivity, differences in average wages are due to differences in average productivity in both groups. In this scenario, men's welfare drop more than in scenario B, with a smallest impact in Colombia (2 p.p.) and the greatest impact in Mexico (9 p.p.) closely followed by Uruguay (8 p.p.). Women, obviously gain from the policy; their welfare increases from 13 p.p. in Peru to 1 p.p. in Colombia. Wage gaps improve after the policy; the higher reduction is found in Mexico and Uruguay (13 and 12 p.p., respectively), and the smaller reduction in Colombia (3 p.p.). This policy does affect unemployment duration and unemployment rates in all countries, but particularly in Mexico. In this country, men/women unemployment ratios increase by 11 p.p. The policy also generates convergence in participation rates. Mexico is once again the country in which the policy has a maximum effect (the ratio falls from 1.47 to 1.19). The smallest effect is found in Colombia, while for the rest of the countries in the sample this effect is between 3 and 10 p.p. 


\section{$5 \quad$ Final Remarks}

In this paper a search model of the labor market with participation decisions, search frictions, match-specific heterogeneity and taste discrimination is estimated in order to identify the impact of pure discrimination from the influence of other gender-specific labor market characteristics such as unobserved productivity and differences in the labor market dynamics by gender. In all the countries, except Colombia, the full flexible model accurately replicates the observed gender wage gaps in the data, not only on average but also at the top and bottom of the wage distribution.

The structure allows the characterization of these countries in terms of job mobility, average productivity and prejudice. The country with the highest mobility rates is by far Peru (with a high arrival rate of job offers and a high separation rate), followed by Chile and Mexico, while the countries with lower mobility are Bolivia and Uruguay. There are high differences in productivity by gender: the highest gaps are found in Chile, Ecuador, Colombia and Paraguay. In terms of prejudice, relative intensity ranges between 0.10 in Ecuador and 0.44 in Mexico. The proportion of prejudiced employers is around $50 \%$ for all the countries.

There is a lot of heterogeneity in the wage gap levels by country, but it is worth noticing that wage gaps are larger at the top of the distribution. A large amount of heterogeneity is found regarding the importance of the different sources of wage gaps: productivity, prejudice and labor market dynamics. Both productivity and prejudice are important sources of gender wage gaps. On average, prejudice is not the main source of wage gaps for skilled workers in all countries. Prejudice matters relatively more in countries such as Bolivia, Mexico, Uruguay, and it is less important in countries such as Ecuador and Paraguay. In Chile, the country with the highest gender wage gap, the relative weight of prejudice is small (less than $50 \%$ of the total wage gap), but it is nevertheless high in absolute terms, generating a gap of 12\%. Both productivity differences and labor dynamics matters. For three countries, Bolivia, Mexico and Uruguay, productivity differences reverse the wage gap favoring women. This effect prevails at the bottom of the wage distribution, but is reversed at the top wages. At the top, productivity is the main force behind wage gaps, while at the bottom there is a lot of heterogeneity regarding the importance of the different sources. But it is at the bottom of the distribution where prejudice generates the wider gaps.

We analyze the potential of two different policies: a hiring subsidy (10\% of d) and an equal-pay policy, finding that by far the most effective policy to reduce wage gaps is the equal-pay policy. The bigger effects of such policy are found in Mexico and Uruguay, where men/women wage ratios drop by 13 and 12 p.p. respectively. The policy also generates convergence in participation rates. 


\section{References}

Altonji, J. and R. Blank, "Race and gender in the labor market," in O. Ashenfelter and D. Card, eds., Handbook of Labor Economics, Vol. 3, Amsterdam: North-Holland, 1999, pp. 3143-3259.

Arceo-Gómez, Eva O. and Raymundo M. Campos-Vázquez, "Evolución de la brecha salarial de género en México," El Trimestre Económico, julio-sep 2014, 0 (323), pp. 619653.

Badel, Alejandro and Ximena Peña, "Decomposing the Gender Wage Gap with Sample Selection Adjustment: Evidence from Colombia," Economic Analysis Review, Diciembre 2010, 25 (2), 169-191.

Blau, F. D., "Trends in the well-being of American women, 1970-1995," Journal of Economic Literature, 1998, 36 (1), 112-165. Article.

_ and L. M. Kahn, "Gender differences in pay," Journal of Economic Perspectives, 2000, 14 (4), 75-99. Article.

Blinder, Alan, "Wage Discrimination - Reduced Form and Structural Estimates," Journal of Human Resources, 1973, 8 (4), 436-455. Article.

Borraz, Fernando and Cecilia Robano, "Brecha Salarial en Uruguay," Economic Analysis Review, June 2010, 25 (1), 49-77.

Carrillo, Paul, Néstor Gandelman, and Virginia Robano, "Sticky floors and glass ceilings in Latin America," The Journal of Economic Inequality, 2014, 12 (3), 339-361. 1573-8701.

DiNardo, John, Nicole M Fortin, and Thomas Lemieux, "Labor Market Institutions and the Distribution of Wages, 1973-1992: A Semiparametric Approach," Econometrica, September 1996, 64 (5), 1001-44.

Eckstein, Zvi and Gerard J. van den Berg, "Empirical labor search: A survey," Journal of Econometrics, February 2007, 136 (2), 531-564.

Firpo, Sergio, Nicole M. Fortin, and Thomas Lemieux, "Unconditional Quantile Regressions," Econometrica, 2009, 77 (3), 953-973.

Flabbi, Luca, "Gender discrimination estimation in a search model with matching and bargaining," International Economic Review, 08 2010, 51 (3), 745-783. 
_ , "Prejudice and gender differentials in the US labor market in the last twenty years," Journal of Econometrics, May 2010, 156 (1), 190-200.

Flinn, C. and J. Heckman, "New methods for analyzing structural models of labor force dynamics," Journal of Econometrics, January 1982, 18 (1), 115-168.

Gunderson, M., "Viewpoint: Male-female wage differentials: how can that be?," Canadian Journal of Economics-Revue Canadienne D Economique, 2006, 39 (1), 1-21. Article.

Juhn, Chinhui, Kevin M Murphy, and Brooks Pierce, "Wage Inequality and the Rise in Returns to Skill," Journal of Political Economy, June 1993, 101 (3), 410-42.

Lopez, Humberto, "The social discount rate : estimates for nine Latin American countries," Policy Research Working Paper Series 4639, The World Bank June 2008.

Machado, José A. F. and José Mata, "Counterfactual decomposition of changes in wage distributions using quantile regression," Journal of Applied Econometrics, 2005, 20 (4), 445-465.

Melly, Blaise, "Decomposition of differences in distribution using quantile regression," Labour Economics, August 2005, 12 (4), 577-590.

Neumark, D., "Employers Discriminatory Behavior and the Estimation of Wage Discrimination," Journal of Human Resources, 1988, 23 (3), 279-295. Article.

Oaxaca, R. L., "Male-female wage differenctials in urban labor markets," International Economic Review, 1973, 14, 693-709.

- and M. R. Ransom, "On Discrimination and the Decomposition of Wage Differentials," Journal of Econometrics, 1994, 61 (1), 5-21. Article.

OECD, "Promoting Productivity for Inclusive Growth in Latin America," Better policies series 4504, OECD February 2016.

Ñopo, Hugo, "Matching as a Tool to Decompose Wage Gaps," Review of Economics and Statistics, 2008, 90 (2), 290-299. doi: 10.1162/rest.90.2.290 0034-6535 doi: 10.1162/rest.90.2.290.

Ñopo, Hugo R., Juan Pablo Atal, and Natalia Winder, "New Century, Old Disparities: Gender and Ethnic Wage Gaps in Latin America," IZA Discussion Papers 5085, Institute for the Study of Labor (IZA) July 2010. 
Figure 1: Participation Rate Gaps (Female / Male)

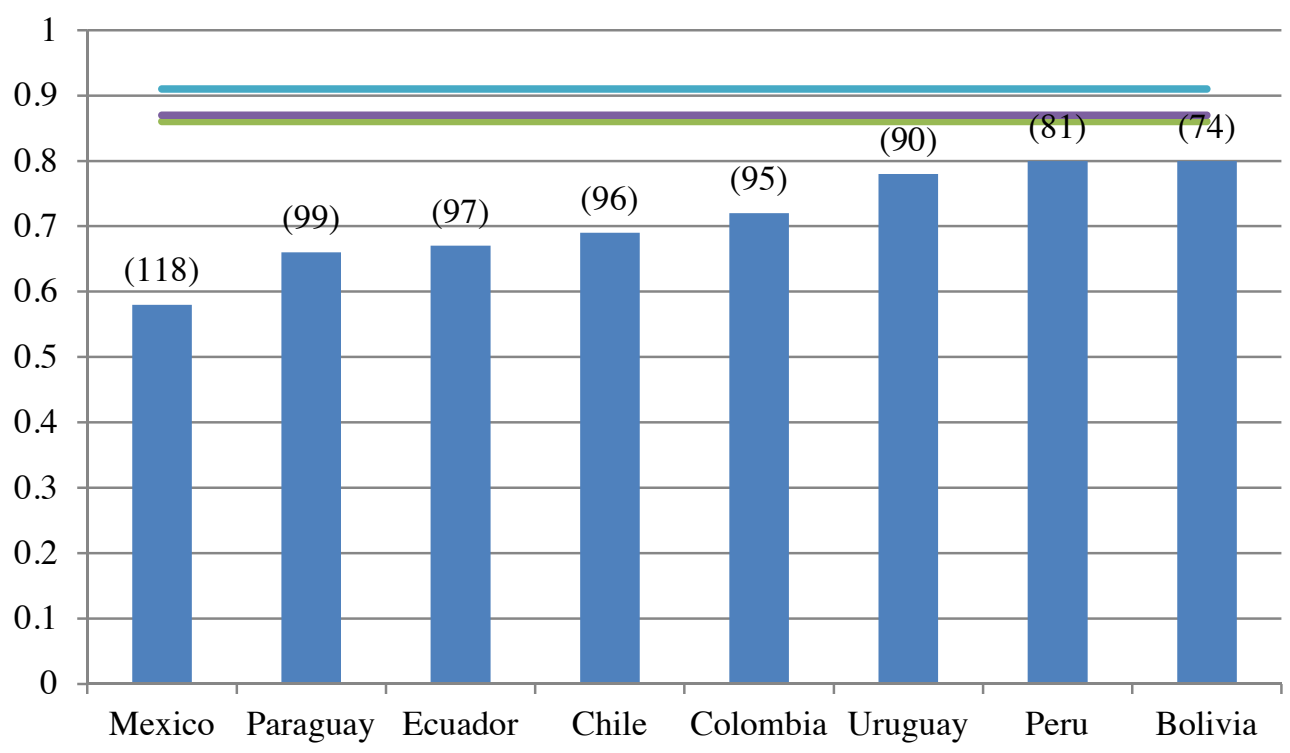

United States (47) $\longrightarrow$ Germany (43) $\longrightarrow$ Canada (25)

Figure 2: Wage Gaps (Female / Male)

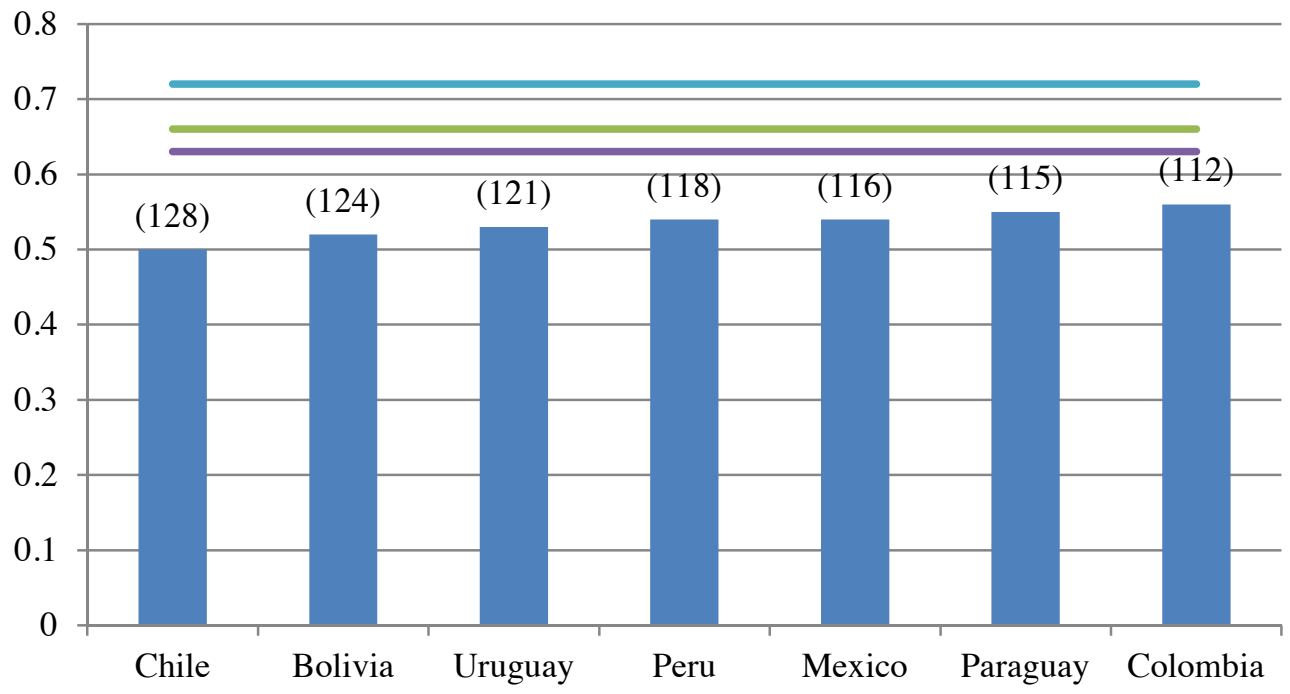

United States (65) — Germany (80) - Canada (27)

Note: Global Gender Gap Report 2014 ranking in parenthesis. 
Figure 3: Employment Gaps in Jobs for High Skilled Workers (Female / Male)

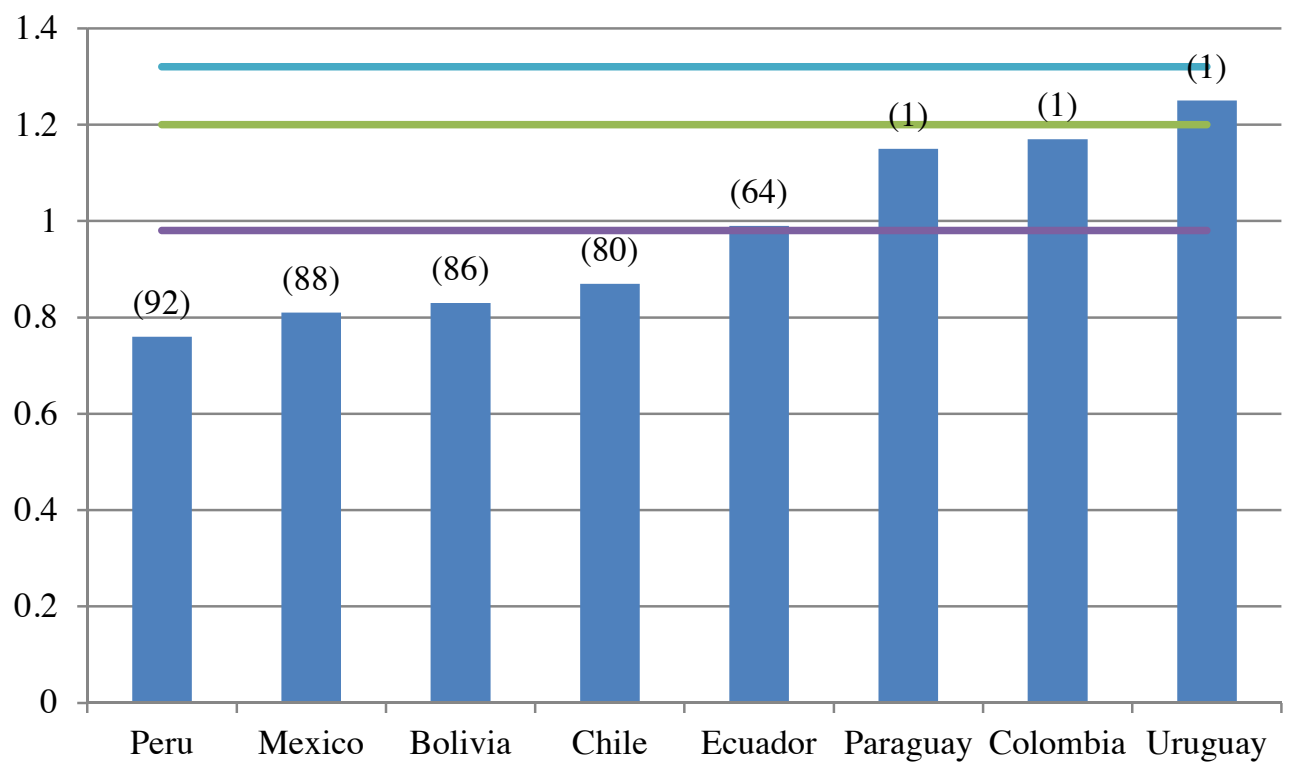

United States (1) $\quad$ Germany (65) $\quad$ Canada (1)

Figure 4: Employment Gaps in the Top Jobs - The Glass Ceiling (Female / Male)

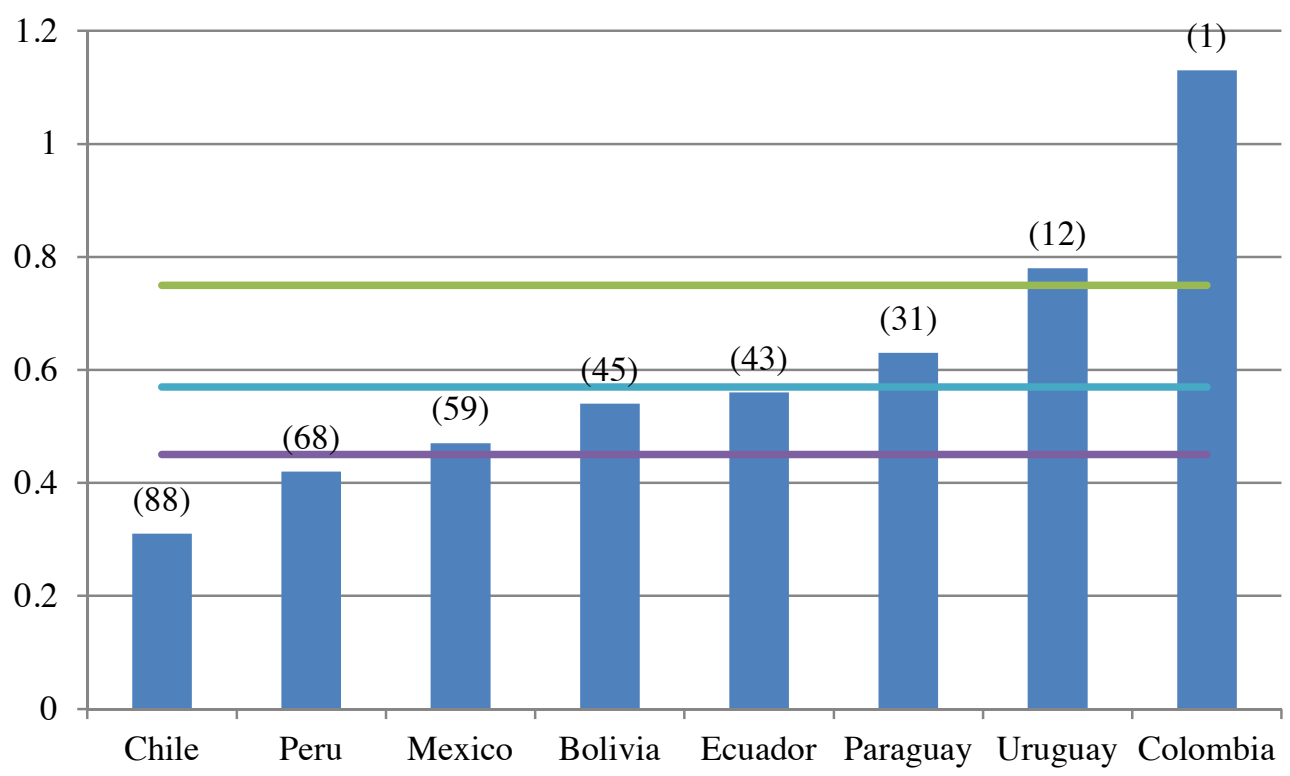

United States (16) $\longrightarrow$ Germany (63) $\quad$ Canada (40)

Note: Global Gender Gap Report 2014 ranking in parenthesis. 
Figure 5: Wages Distribution (Non-Parametric Estimation) - Bolivia

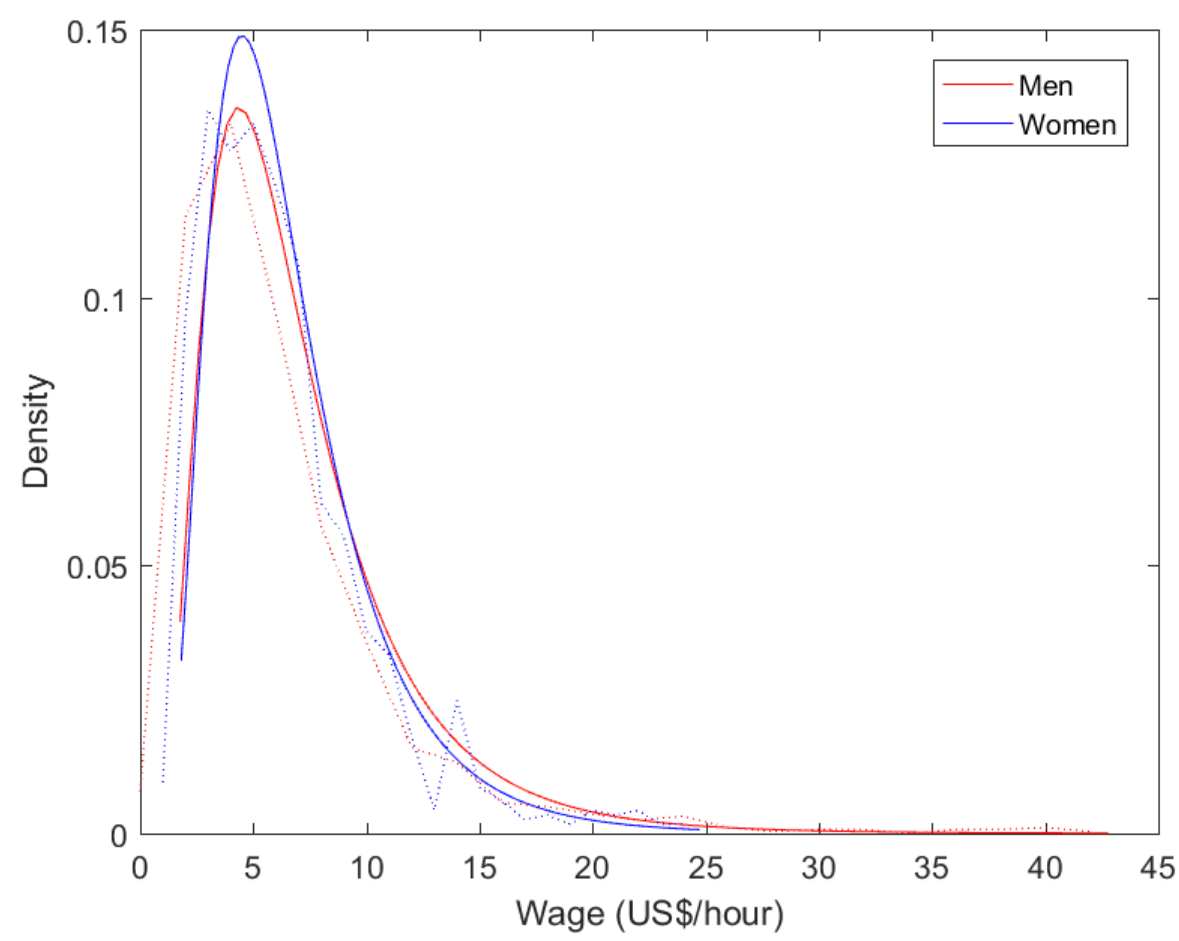

Figure 6: Wages Distribution (Non-Parametric Estimation) - Chile

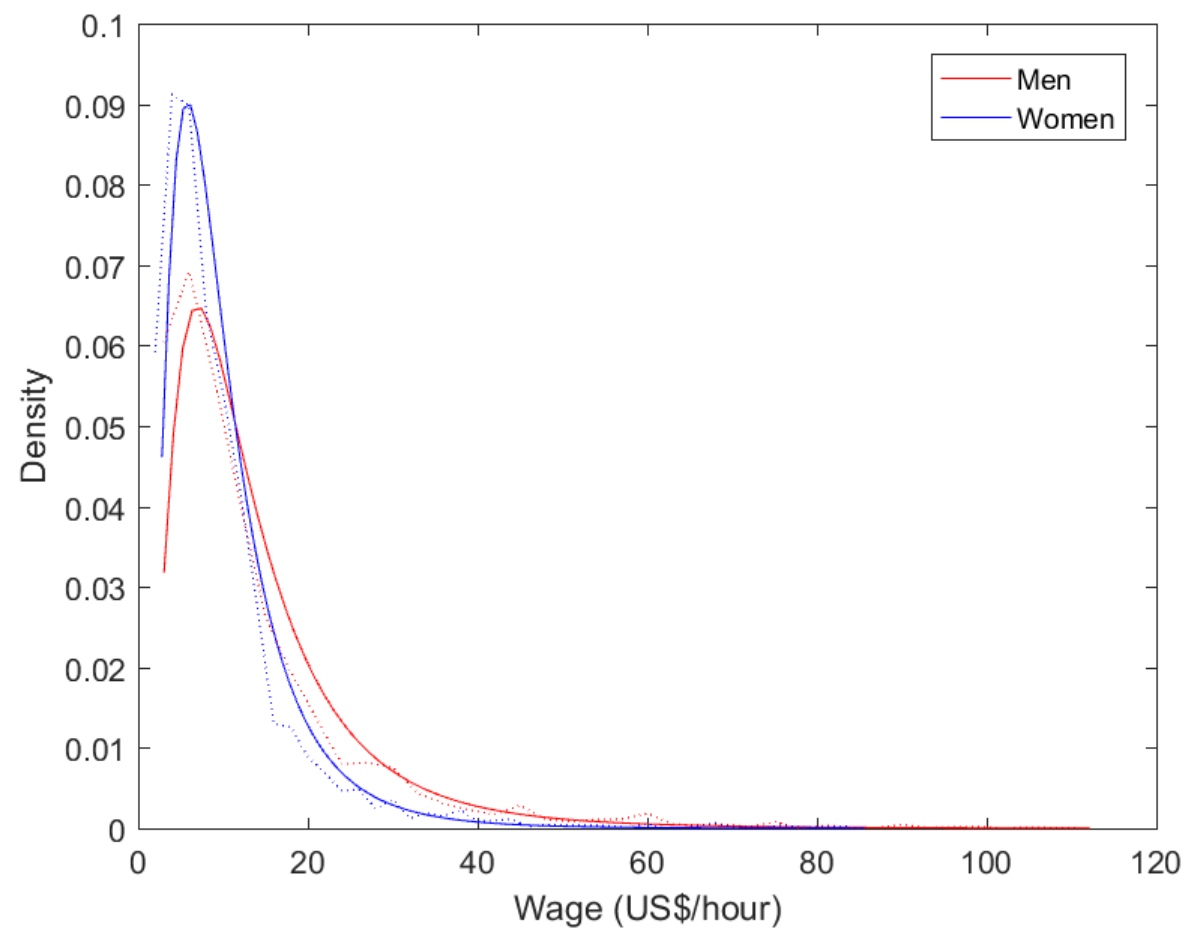


Figure 7: Wages Distribution (Non-Parametric Estimation) - Colombia

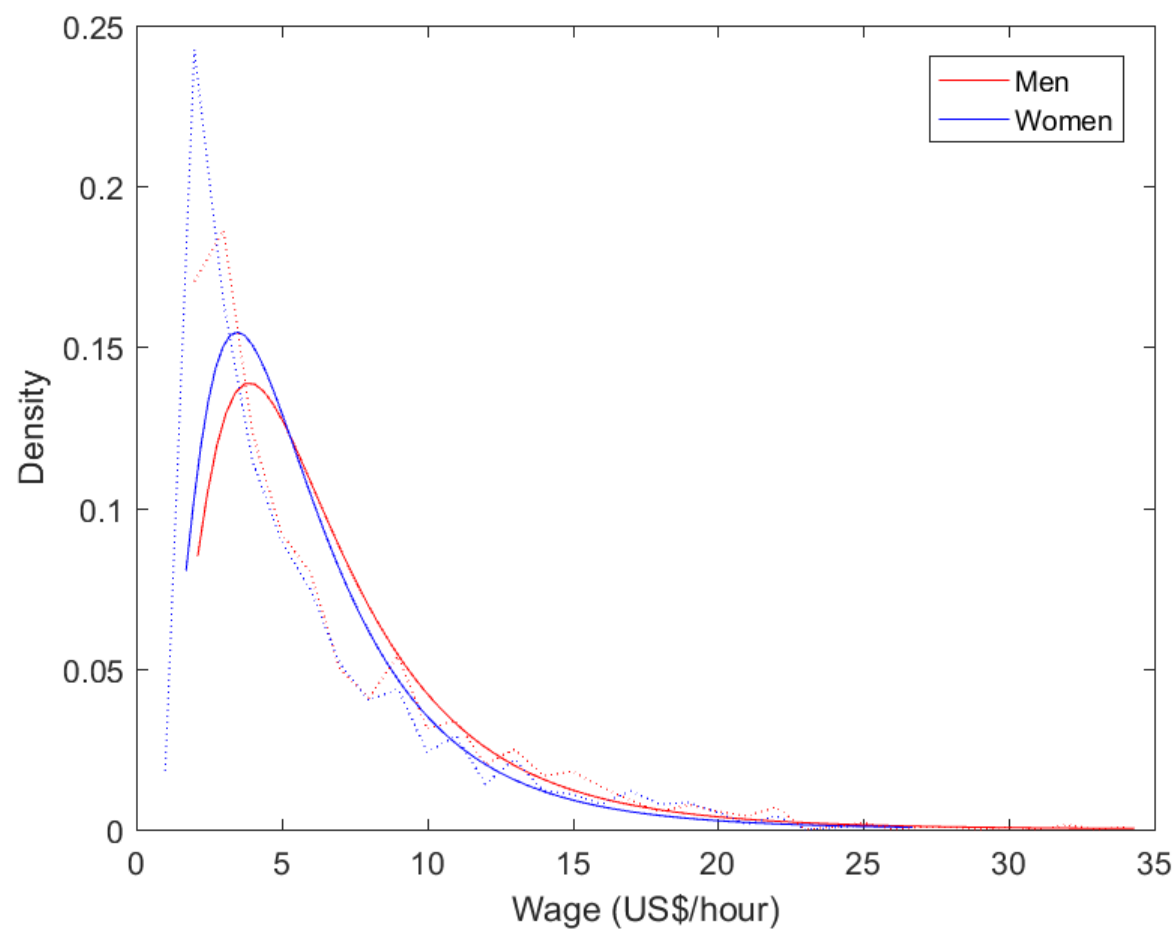

Figure 8: Wages Distribution (Non-Parametric Estimation) - Ecuador

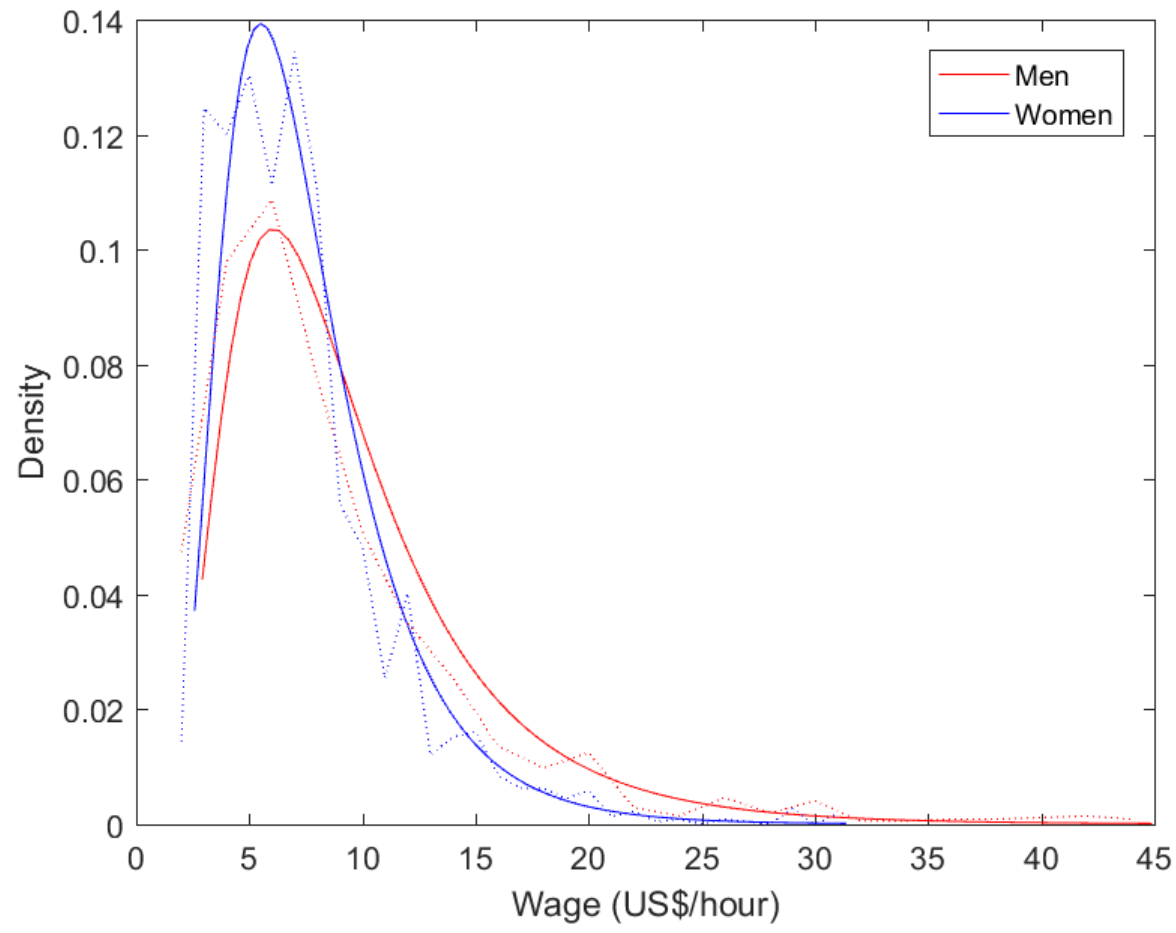


Figure 9: Wages Distribution (Non-Parametric Estimation) - Mexico

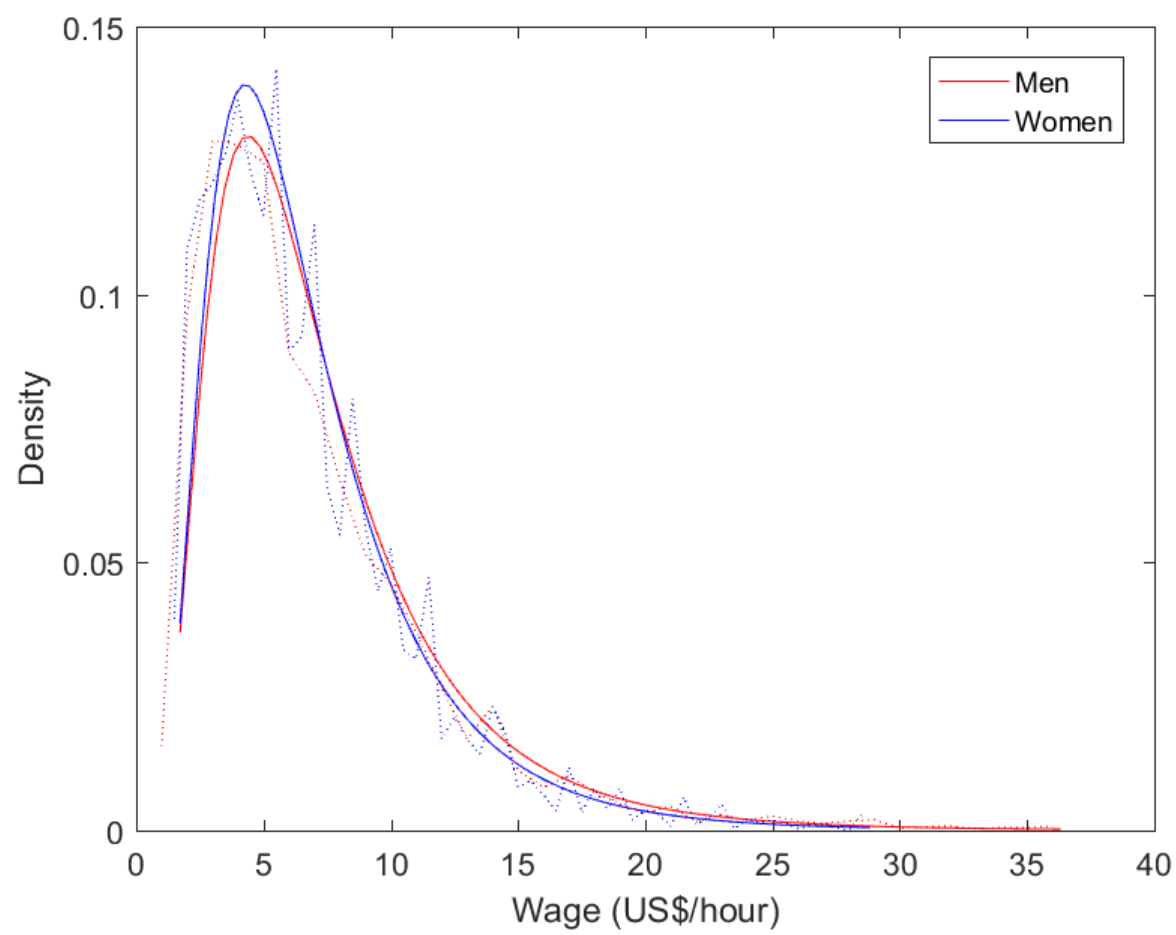

Figure 10: Wages Distribution (Non-Parametric Estimation) - Paraguay

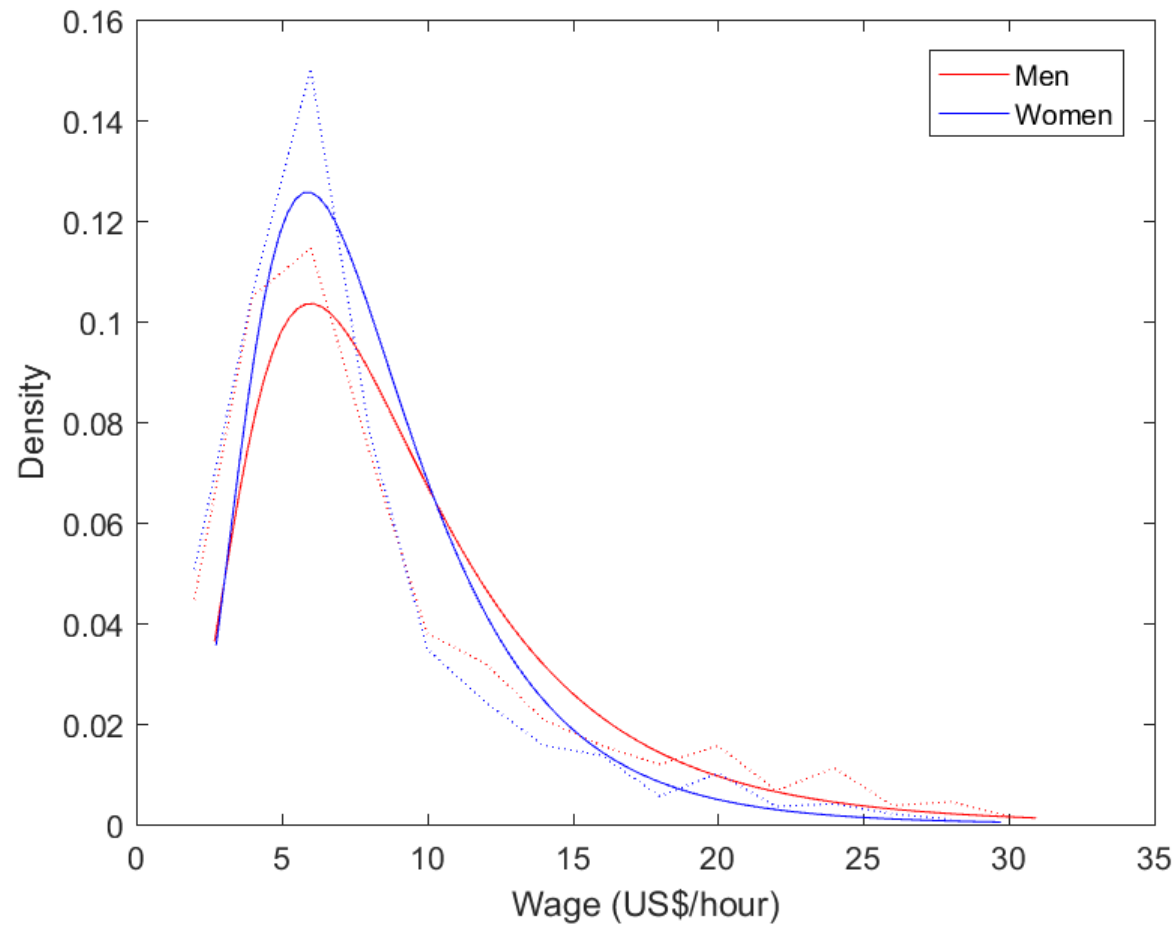


Figure 11: Wages Distribution (Non-Parametric Estimation) - Peru

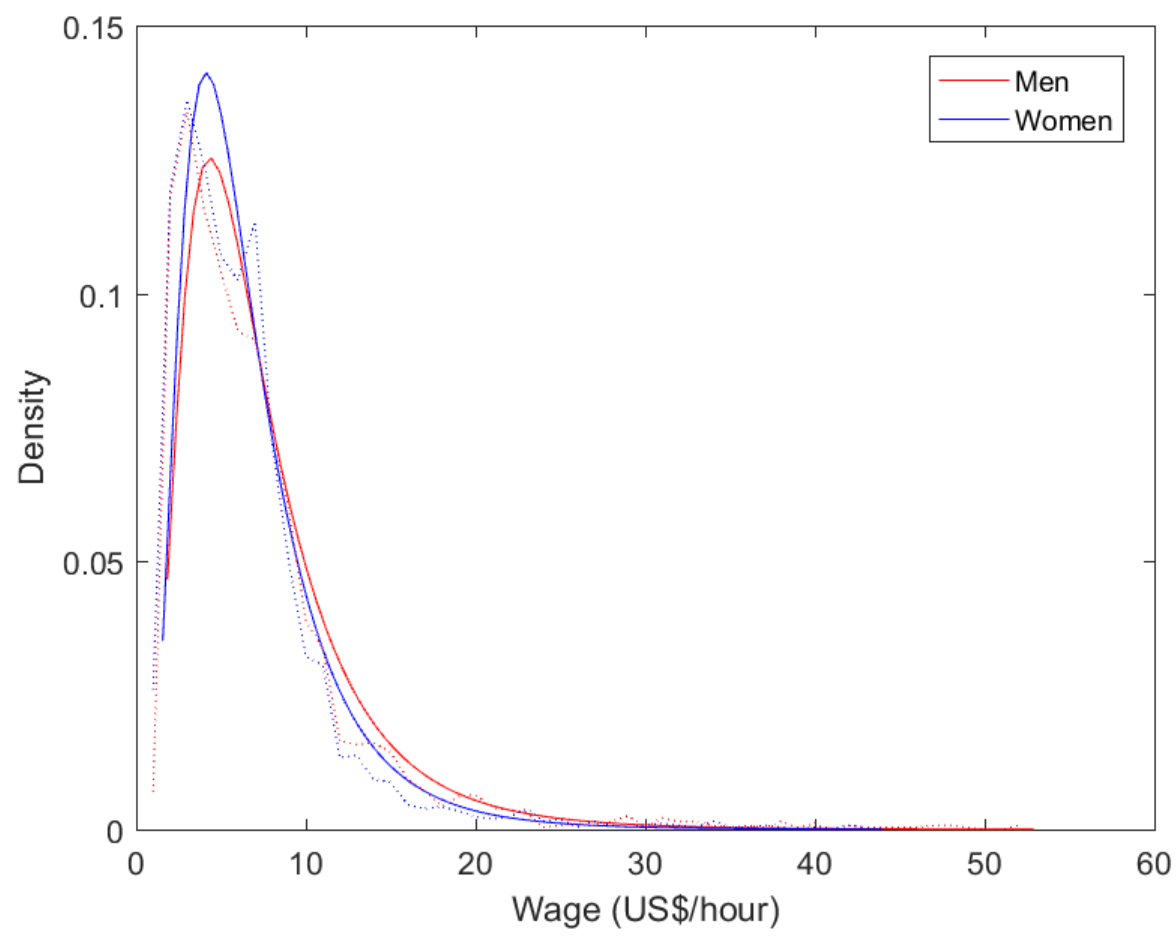

Figure 12: Wages Distribution (Non Parametric Estimation) - Uruguay

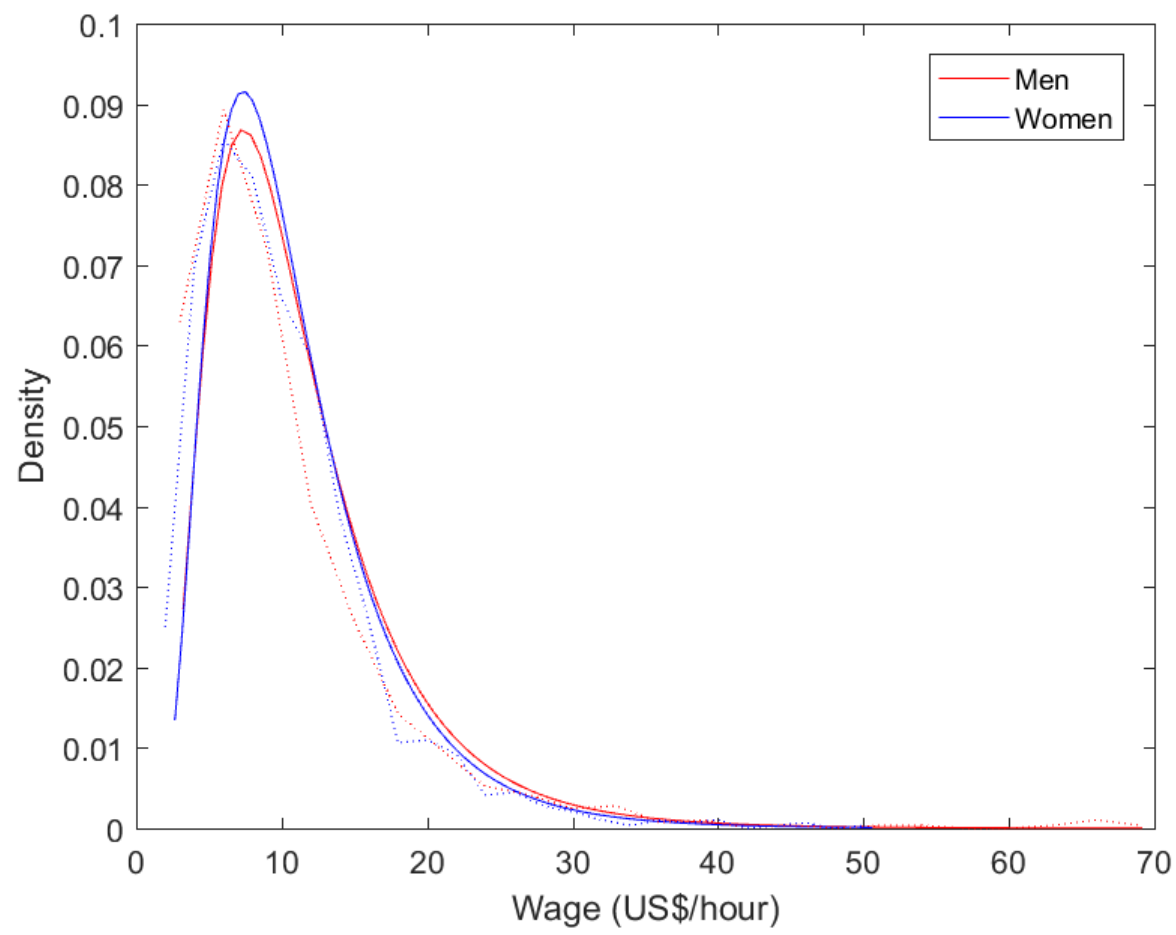


Figure 13: Gender Discrimination Intensity

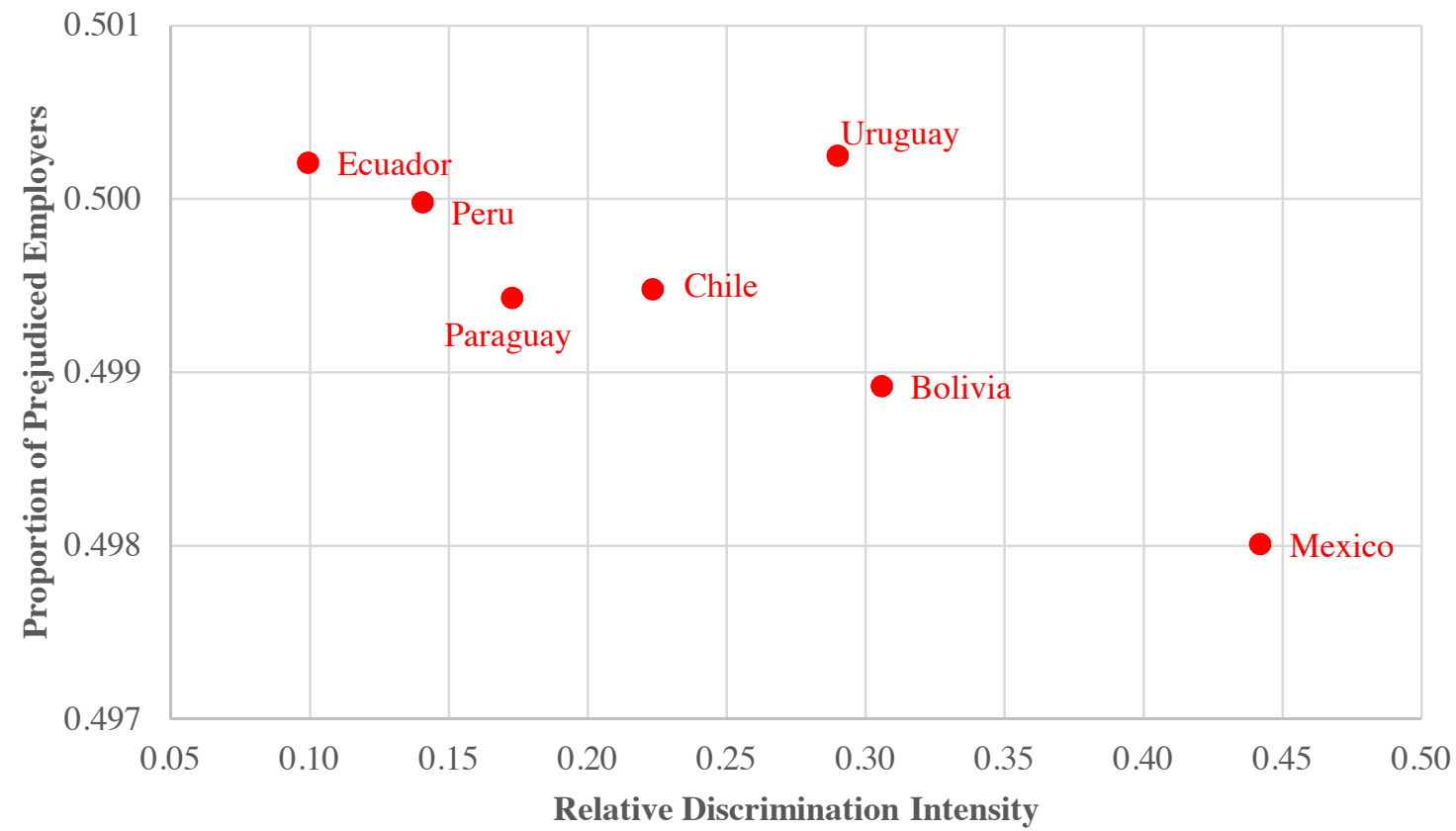

(*) Relative Discrimination intensity is defined as the ratio between the discrimination intensity parameter $(d)$ and the average productivity of men $(E[x / M])$ 


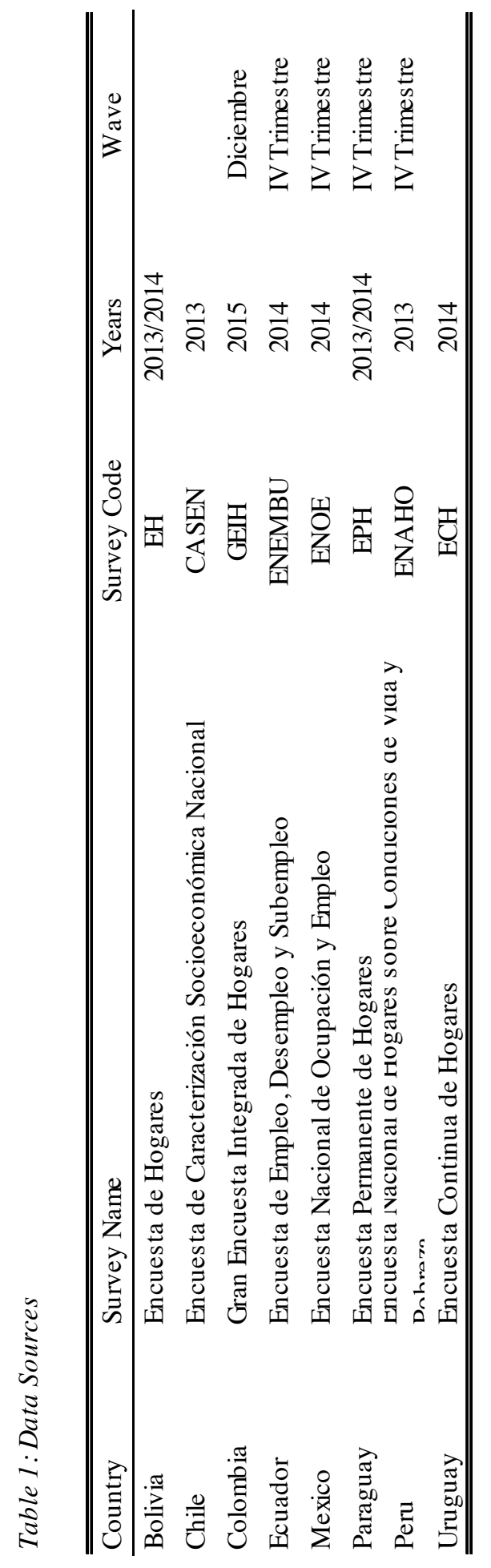


Table 2: Skilled Workers. Formal Workers and Wage Earners

\begin{tabular}{lcccccccc}
\hline \hline & Bolivia & Chile & Colombia & Ecuador & Mexico & Paraguay & Peru & Uruguay \\
\hline \multicolumn{7}{c}{ Formal Employees/(Formal Employees + Informal Employees)(*) } \\
\hline Men & $91.0 \%$ & $95.1 \%$ & $93.2 \%$ & $94.0 \%$ & $88.1 \%$ & $87.0 \%$ & $88.1 \%$ & $96.8 \%$ \\
Women & $90.1 \%$ & $94.0 \%$ & $91.5 \%$ & $94.0 \%$ & $88.9 \%$ & $86.7 \%$ & $89.5 \%$ & $96.6 \%$ \\
\hline Employees/(Employees + Self Employed Workers) \\
\hline Men & $80.2 \%$ & $87.5 \%$ & $67.1 \%$ & $82.4 \%$ & $86.2 \%$ & $85.2 \%$ & $80.2 \%$ & $77.7 \%$ \\
Women & $81.0 \%$ & $91.0 \%$ & $70.7 \%$ & $89.2 \%$ & $88.5 \%$ & $88.8 \%$ & $80.6 \%$ & $83.8 \%$ \\
\hline \hline
\end{tabular}

(*) In all countries, except Ecuador and Uruguay, a formal employee is defined as a worker with an explicit job contract. In Ecuador and Uruguay, contributions to the social security system is used to define formal employees. 
Table 3: Unemployment Duration (Months)

\begin{tabular}{lccccc}
\hline \hline & No. Obs & Average & $\begin{array}{c}\text { Standard } \\
\text { Deviation }\end{array}$ & Minimum & Maximum \\
\hline \multicolumn{5}{c}{ Men } \\
\hline Bolivia & 44 & 5.36 & 5.82 & 0.25 & 24.00 \\
Chile & 307 & 2.95 & 3.61 & 0.25 & 26.00 \\
Colombia & 210 & 4.75 & 5.59 & 0.25 & 34.00 \\
Ecuador & 53 & 4.00 & 3.95 & 0.25 & 13.00 \\
Mexico & 663 & 3.07 & 3.76 & 0.01 & 34.57 \\
Paraguay & 17 & 5.06 & 4.64 & 0.25 & 12.00 \\
Peru & 118 & 1.01 & 1.38 & 0.25 & 12.00 \\
Uruguay & 30 & 7.47 & 7.92 & 0.01 & 32.00 \\
\hline \multicolumn{5}{c}{ Women } & \\
\hline Bolivia & 41 & 12.11 & 11.79 & 0.50 & 36.00 \\
Chile & 391 & 3.04 & 3.92 & 0.25 & 25.00 \\
Colombia & 462 & 4.86 & 6.13 & 0.25 & 32.00 \\
Ecuador & 103 & 4.46 & 3.98 & 0.25 & 13.00 \\
Mexico & 649 & 2.97 & 3.61 & 0.01 & 32.70 \\
Paraguay & 24 & 9.83 & 7.67 & 1.00 & 24.00 \\
Peru & 194 & 0.96 & 0.89 & 0.25 & 6.00 \\
Uruguay & 47 & 7.87 & 6.89 & 0.01 & 30.00 \\
\hline \hline
\end{tabular}

Table 4: Hourly Wages (PPP US Dollars/Hour)

\begin{tabular}{lccccc}
\hline \hline & No. Obs & Average & $\begin{array}{c}\text { Standard } \\
\text { Deviation }\end{array}$ & Minimum & Maximum \\
\hline \multicolumn{5}{c}{ Men } \\
\hline Bolivia & 1404 & 7.22 & 5.08 & 1.77 & 42.78 \\
Chile & 4671 & 14.65 & 12.86 & 3.05 & 112.17 \\
Colombia & 1444 & 6.90 & 4.79 & 2.12 & 34.32 \\
Ecuador & 1730 & 9.61 & 6.34 & 2.92 & 44.89 \\
Mexico & 7497 & 7.43 & 4.89 & 1.73 & 36.33 \\
Paraguay & 672 & 9.53 & 5.84 & 2.70 & 30.93 \\
Peru & 2778 & 7.70 & 5.94 & 1.84 & 52.90 \\
Uruguay & 959 & 11.54 & 7.85 & 3.23 & 69.17 \\
\hline \multicolumn{5}{c}{ Women } & \\
\hline Bolivia & 1170 & 6.77 & 3.79 & 1.82 & 24.72 \\
Chile & 5288 & 10.67 & 8.84 & 2.81 & 85.69 \\
Colombia & 1921 & 6.20 & 4.37 & 1.72 & 26.69 \\
Ecuador & 2240 & 7.67 & 4.03 & 2.58 & 31.38 \\
Mexico & 8422 & 6.97 & 4.23 & 1.72 & 28.83 \\
Paraguay & 988 & 8.38 & 4.59 & 2.75 & 29.72 \\
Peru & 2607 & 6.88 & 4.79 & 1.57 & 43.96 \\
Uruguay & 1459 & 11.00 & 6.14 & 2.66 & 50.62 \\
\hline \hline
\end{tabular}


Table 5: Skilled workers. Non-Parametric Wage Gaps Decompositions (Nopo, 2008

\begin{tabular}{lrrrrr}
\hline \hline & Raw Wage & \multicolumn{5}{c}{$\begin{array}{c}\text { Unexplained Gap } \\
\text { Educ-Age- } \\
\text { formal }\end{array}$} & $\begin{array}{c}\text { Educ-Age- } \\
\text { ocup }\end{array}$ & $\begin{array}{c}\text { Educ-Age- } \\
\text { ocup-sector }\end{array}$ \\
\hline Gap & Educ-Age & \multicolumn{5}{c}{ Salaried Workers } \\
Bolivia & $5.5 \%$ & $5.2 \%$ & $4.5 \%$ & $7.1 \%$ & $6.1 \%$ \\
Chile & $39.8 \%$ & $37.0 \%$ & $36.7 \%$ & $34.0 \%$ & $23.8 \%$ \\
Colombia & $3.0 \%$ & $9.8 \%$ & $10.7 \%$ & $2.1 \%$ & $-0.4 \%$ \\
Ecuador & $22.0 \%$ & $23.3 \%$ & $24.2 \%$ & $22.3 \%$ & $21.1 \%$ \\
Mexico & $4.0 \%$ & $-0.1 \%$ & $0.8 \%$ & $2.1 \%$ & $2.4 \%$ \\
Paraguay & $9.7 \%$ & $9.2 \%$ & $10.3 \%$ & $7.6 \%$ & $4.8 \%$ \\
Peru & $9.8 \%$ & $13.2 \%$ & $13.8 \%$ & $14.8 \%$ & $10.4 \%$ \\
Uruguay & $4.6 \%$ & $9.2 \%$ & $8.4 \%$ & $9.2 \%$ & $4.0 \%$ \\
\hline \hline
\end{tabular}


Table 6: Estimated Parameters (Best Model)

\begin{tabular}{|c|c|c|c|c|c|c|c|c|}
\hline Parameter & Bolivia & Chile & Colombia & Ecuador & Mexico & Paraguay & Peru & Uruguay \\
\hline \multirow[t]{2}{*}{$\lambda_{M}$} & 0.1879 & 0.3460 & 0.2265 & 0.2560 & 0.3281 & 0.2003 & 1.0017 & 0.1353 \\
\hline & $(0.0283)$ & $(0.0198)$ & $(0.0158)$ & $(0.0064)$ & $(0.0001)$ & $(0.0017)$ & $(0.0922)$ & $(0.0247)$ \\
\hline \multirow[t]{2}{*}{$\lambda_{W}$} & 0.0868 & 0.3784 & 0.2129 & 0.2289 & 0.3764 & 0.1055 & 1.0619 & 0.1307 \\
\hline & $(0.0140)$ & $(0.0669)$ & $(0.0099)$ & $(0.0005)$ & $(0.0001)$ & $(0.0007)$ & $(0.0783)$ & $(0.0192)$ \\
\hline \multirow[t]{2}{*}{$\eta_{M}$} & 0.0058 & 0.0223 & 0.0306 & 0.0077 & 0.0288 & 0.0050 & 0.0420 & 0.0042 \\
\hline & $(0.0013)$ & $(0.0018)$ & $(0.0031)$ & $(0.0000)$ & $(0.0000)$ & $(0.0000)$ & $(0.0055)$ & $(0.0011)$ \\
\hline \multirow[t]{2}{*}{$\eta_{W}$} & 0.0029 & 0.0243 & 0.0495 & 0.0103 & 0.0260 & 0.0025 & 0.0773 & 0.0041 \\
\hline & $(0.0006)$ & $(0.0018)$ & $(0.0034)$ & $(0.0001)$ & $(0.0000)$ & $(0.0000)$ & $(0.0080)$ & $(0.0009)$ \\
\hline \multirow[t]{2}{*}{$\mu_{M}$} & 2.2842 & 2.8782 & 2.0346 & 2.5164 & 2.3196 & 2.5442 & 2.3089 & 2.7462 \\
\hline & $(0.0195)$ & $(0.0138)$ & $(0.0304)$ & $(0.0829)$ & $(0.0021)$ & $(0.0164)$ & $(0.0151)$ & $(0.0229)$ \\
\hline \multirow[t]{2}{*}{$\sigma_{M}$} & 0.7056 & 0.8680 & 0.8758 & 0.7193 & 0.7217 & 0.7009 & 0.7570 & 0.6781 \\
\hline & $(0.0148)$ & $(0.0109)$ & $(0.0235)$ & $(0.0216)$ & $(0.0015)$ & $(0.0156)$ & $(0.0117)$ & $(0.0175)$ \\
\hline \multirow[t]{2}{*}{$\mu_{W}$} & 2.4348 & 2.6633 & 2.0203 & 2.4312 & 2.4792 & 2.5494 & 2.3494 & 2.9452 \\
\hline & $(0.0894)$ & $(0.0373)$ & $(0.0211)$ & $(0.0447)$ & $(0.0012)$ & $(0.0020)$ & $(0.0560)$ & $(0.0782)$ \\
\hline \multirow[t]{2}{*}{$\sigma_{W}$} & 0.5370 & 0.7521 & 0.8083 & 0.5659 & 0.5692 & 0.5604 & 0.6419 & 0.5167 \\
\hline & $(0.0411)$ & $(0.0233)$ & $(0.0167)$ & $(0.0841)$ & $(0.0006)$ & $(0.0009)$ & $(0.0294)$ & $(0.0347)$ \\
\hline \multirow[t]{2}{*}{$d$} & 3.8505 & 5.7899 & . & 1.5949 & 5.8334 & 2.8125 & 1.8847 & 5.6862 \\
\hline & (1.9669) & $(8.8590)$ & . & $(0.0250)$ & $(0.0036)$ & $(0.0287)$ & (1.5974) & $(2.0440)$ \\
\hline \multirow[t]{2}{*}{$p$} & 0.4989 & 0.4995 & . & 0.5002 & 0.4980 & 0.4994 & 0.5000 & 0.5003 \\
\hline & $(0.3665)$ & $(0.3237)$ & . & $(0.6408)$ & $(0.0358)$ & $(0.4904)$ & $(0.5510)$ & $(0.3339)$ \\
\hline$w_{M}{ }^{*}$ & 1.766 & 3.0467 & 2.1163 & 2.9233 & 1.7257 & 2.6955 & 1.8418 & 3.2324 \\
\hline$w_{W} *$ & 1.8161 & 2.8062 & 1.7159 & 2.5816 & 1.7214 & 2.7495 & 1.5667 & 2.6626 \\
\hline$\gamma_{M}$ & 1.4800 & 0.9867 & 1.4037 & 1.2817 & 1.4618 & 1.2664 & 1.6305 & 1.0969 \\
\hline$\gamma_{W}$ & 0.8630 & 0.6201 & 0.9803 & 0.7484 & 0.5695 & 0.8112 & 1.0357 & 0.8205 \\
\hline Obs & 2659 & 10657 & 4037 & 4126 & 17231 & 1701 & 5697 & 2495 \\
\hline $\log \mathrm{L}$ & -7302 & -36180 & -12034 & -11742 & -49667 & -4886 & -15899 & -7911 \\
\hline
\end{tabular}

Note: Asymptotic standar errors in parenthesis. 
Table 7: Predictions (Best Model)

\begin{tabular}{|c|c|c|c|c|c|c|c|c|}
\hline & Bolivia & Chile & Colombia & Ecuador & Mexico & Paraguay & Peru & Uruguay \\
\hline \multicolumn{9}{|c|}{ Men } \\
\hline \multicolumn{9}{|c|}{ Average Productivity: } \\
\hline Model & 12.5930 & 25.9190 & 11.2250 & 16.0400 & 13.1980 & 16.2790 & 13.4020 & 19.6120 \\
\hline Data & - & - & - & - & - & - & - & - \\
\hline \multicolumn{9}{|c|}{ Stand ar Deviation of Productivity: } \\
\hline Model & 10.1163 & 27.4825 & 12.0553 & 13.2042 & 10.9105 & 12.9653 & 11.7873 & 14.9840 \\
\hline Data & - & - & - & - & - & - & - & - \\
\hline \multicolumn{9}{|c|}{ Average Wage: } \\
\hline Model & 7.2221 & 14.7370 & 7.0428 & 9.6389 & 7.5033 & 9.5828 & 7.6972 & 11.5090 \\
\hline Data & 7.2166 & 14.6537 & 6.8953 & 9.6107 & 7.4265 & 9.5298 & 7.6976 & 11.5440 \\
\hline \multicolumn{9}{|c|}{ Hazard Rate Out of Unemployment: } \\
\hline Model & 0.1864 & 0.3388 & 0.2104 & 0.2503 & 0.3258 & 0.1977 & 0.9893 & 0.1339 \\
\hline Data & 0.1864 & 0.3388 & 0.2104 & 0.2503 & 0.3258 & 0.1977 & 0.9895 & 0.1339 \\
\hline \multicolumn{9}{|c|}{ Unemployment Rate: } \\
\hline Model & 0.0304 & 0.0617 & 0.1270 & 0.0297 & 0.0813 & 0.0247 & 0.0407 & 0.0303 \\
\hline Data & 0.0304 & 0.0617 & 0.1270 & 0.0297 & 0.0813 & 0.0247 & 0.0407 & 0.0303 \\
\hline \multicolumn{9}{|c|}{ Unemployment Duration: } \\
\hline Model & 5.3637 & 2.9519 & 4.7538 & 3.9950 & 3.0692 & 5.0594 & 1.0108 & 7.4677 \\
\hline Data & 5.3636 & 2.9520 & 4.7536 & 3.9953 & 3.0693 & 5.0588 & 1.0106 & 7.4673 \\
\hline \multicolumn{9}{|c|}{ Women } \\
\hline \multicolumn{9}{|c|}{ Average Productivity: } \\
\hline Model & 13.1830 & 19.0330 & 10.4540 & 13.3470 & 14.0300 & 14.9760 & 12.8770 & 21.7300 \\
\hline Data & - & - & - & - & - & - & - & - \\
\hline \multicolumn{9}{|c|}{ Standar Deviation of Productivity: } \\
\hline Model & 7.6210 & 16.6000 & 10.0374 & 8.1998 & 8.6777 & 9.0960 & 9.1955 & 12.0208 \\
\hline Data & - & - & - & - & - & - & - & - \\
\hline \multicolumn{9}{|c|}{ Average Wage: } \\
\hline Model & 6.7702 & 10.6250 & 6.2438 & 7.6771 & 6.9819 & 8.3632 & 6.8657 & 10.9940 \\
\hline Data & 6.7664 & 10.6729 & 6.2016 & 7.6709 & 6.9672 & 8.3784 & 6.8807 & 10.9993 \\
\hline \multicolumn{9}{|c|}{ Hazard Rate Out of Unemployment: } \\
\hline Model & 0.0826 & 0.3287 & 0.2058 & 0.2240 & 0.3368 & 0.1017 & 1.0388 & 0.1270 \\
\hline Data & 0.0826 & 0.3287 & 0.2058 & 0.2240 & 0.3368 & 0.1017 & 1.0389 & 0.1270 \\
\hline \multicolumn{9}{|c|}{ Unemployment Rate: } \\
\hline Model & 0.0339 & 0.0689 & 0.1939 & 0.0440 & 0.0716 & 0.0237 & 0.0693 & 0.0312 \\
\hline Data & 0.0339 & 0.0689 & 0.1939 & 0.0440 & 0.0715 & 0.0237 & 0.0693 & 0.0312 \\
\hline \multicolumn{9}{|c|}{ Unemployment Duration: } \\
\hline Model & 12.1092 & 3.0422 & 4.8598 & 4.4635 & 2.9691 & 9.8338 & 0.9626 & 7.8734 \\
\hline Data & 12.1098 & 3.0422 & 4.8598 & 4.4636 & 2.9692 & 9.8333 & 0.9626 & 7.8732 \\
\hline
\end{tabular}


Table 8: Gender Wage Gaps Decomposition (Best Model)

\begin{tabular}{|c|c|c|c|c|}
\hline & \multicolumn{3}{|c|}{ Wages } & \multirow[t]{3}{*}{ Participation } \\
\hline & Entire & Bottom & Top & \\
\hline & Dis tribution & $25 \%$ & $25 \%$ & \\
\hline & (1) & $(2)$ & (3) & (4) \\
\hline & \multicolumn{4}{|c|}{ Bolivia } \\
\hline Productivity & 1.0552 & 1.3113 & 0.9234 & 0.8952 \\
\hline Prejudice & 0.8561 & 0.6489 & 0.9286 & 0.5746 \\
\hline Transitions & 0.8719 & 0.6902 & 0.9334 & 0.0001 \\
\hline All Parameters & 0.9374 & 1.0190 & 0.8647 & 0.8539 \\
\hline \multirow[t]{2}{*}{ Data } & 0.9376 & 1.0105 & 0.8769 & 0.8539 \\
\hline & \multicolumn{4}{|c|}{ Chile } \\
\hline Productivity & 0.6458 & 0.5843 & 0.6372 & 0.0001 \\
\hline Prejudice & 0.8829 & 0.6348 & 0.9514 & 0.5623 \\
\hline Transitions & 1.0538 & 1.1620 & 1.0269 & 0.9676 \\
\hline All Parameters & 0.7210 & 0.8202 & 0.6765 & 0.8674 \\
\hline \multirow[t]{2}{*}{ Data } & 0.7283 & 0.8194 & 0.6899 & 0.8674 \\
\hline & \multicolumn{4}{|c|}{ Colombia } \\
\hline Productivity & 0.8801 & 0.8707 & 0.8638 & 0.8460 \\
\hline Prejudice & 1.0000 & 1.0000 & 1.0000 & 0.9216 \\
\hline Transitions & 0.8470 & 0.6098 & 0.9203 & 0.5107 \\
\hline All Parameters & 0.8866 & 0.8876 & 0.8671 & 0.8580 \\
\hline \multirow[t]{2}{*}{ Data } & 0.8994 & 0.9153 & 0.9193 & 0.8580 \\
\hline & \multicolumn{4}{|c|}{ Ecuador } \\
\hline Productivity & 0.7658 & 0.8310 & 0.7079 & 0.6689 \\
\hline Prejudice & 0.9466 & 0.8823 & 0.9722 & 0.8652 \\
\hline Transitions & 0.9343 & 0.8420 & 0.9656 & 0.7779 \\
\hline All Parameters & 0.7965 & 0.9093 & 0.7235 & 0.8758 \\
\hline \multirow[t]{2}{*}{ Data } & 0.7982 & 0.9060 & 0.7266 & 0.8758 \\
\hline & \multicolumn{4}{|c|}{ Mexico } \\
\hline Productivity & 1.0878 & 1.3524 & 0.9590 & 0.7893 \\
\hline Prejudice & 0.7717 & 0.3981 & 0.8910 & 0.0001 \\
\hline Transitions & 1.1146 & 1.3019 & 1.0587 & 0.8911 \\
\hline All Parameters & 0.9305 & 0.9543 & 0.8819 & 0.6793 \\
\hline \multirow[t]{2}{*}{ Data } & 0.9381 & 0.9573 & 0.9013 & 0.6793 \\
\hline & \multicolumn{4}{|c|}{ Paraguay } \\
\hline Productivity & 0.8880 & 1.0075 & 0.8106 & 0.8359 \\
\hline Prejudice & 0.9125 & 0.8028 & 0.9546 & 0.8317 \\
\hline Transitions & 0.8494 & 0.6488 & 0.9206 & 0.0001 \\
\hline All Parameters & 0.8727 & 0.9822 & 0.8022 & 0.9229 \\
\hline \multirow[t]{2}{*}{ Data } & 0.8792 & 0.9857 & 0.8154 & 0.9229 \\
\hline & \multicolumn{4}{|c|}{ Peru } \\
\hline Productivity & 0.9285 & 1.0218 & 0.8672 & 0.8070 \\
\hline Prejudice & 0.9006 & 0.7452 & 0.9511 & 0.7085 \\
\hline Transitions & 0.8706 & 0.6656 & 0.9349 & 0.0001 \\
\hline All Parameters & 0.8920 & 0.9341 & 0.8491 & 0.8445 \\
\hline \multirow[t]{2}{*}{ Data } & 0.8939 & 0.9328 & 0.8499 & 0.8445 \\
\hline & \multicolumn{4}{|c|}{ Uruguay } \\
\hline Productivity & 1.1324 & 1.3947 & 0.9910 & 0.9995 \\
\hline Prejudice & 0.8606 & 0.6848 & 0.9277 & 0.8066 \\
\hline Transitions & 0.9857 & 0.9659 & 0.9924 & 0.9385 \\
\hline All Parameters & 0.9552 & 0.9756 & 0.8998 & 0.9138 \\
\hline Data & 0.9528 & 0.9728 & 0.8882 & 0.9138 \\
\hline
\end{tabular}


Table 9: Policy Simulations

\begin{tabular}{|c|c|c|c|c|c|c|c|c|}
\hline & Bolivia & Chile & Colombia & Ecuador & México & Paraguay & Perú & Uruguay \\
\hline \multicolumn{9}{|c|}{ Panel A: Base Model } \\
\hline \multicolumn{9}{|l|}{ Welfare Measures } \\
\hline Men & 1.00 & 1.00 & 1.00 & 1.00 & 1.00 & 1.00 & 1.00 & 1.00 \\
\hline Women & 0.96 & 0.72 & 0.74 & 0.78 & 0.97 & 0.89 & 0.73 & 0.95 \\
\hline Total & 0.98 & 0.85 & 0.85 & 0.87 & 0.98 & 0.94 & 0.87 & 0.97 \\
\hline \multicolumn{9}{|c|}{ Labor Market Variables (Men/Women) } \\
\hline Reservation Wage & 0.97 & 1.09 & 1.23 & 1.13 & 1.00 & 0.98 & 1.18 & 1.21 \\
\hline Average Wage & 1.07 & 1.39 & 1.13 & 1.26 & 1.07 & 1.15 & 1.12 & 1.05 \\
\hline Unemployment Dura & 0.44 & 0.97 & 0.98 & 0.90 & 1.03 & 0.51 & 1.05 & 0.95 \\
\hline Unemployment Rate & 0.90 & 0.90 & 0.65 & 0.68 & 1.14 & 1.04 & 0.59 & 0.97 \\
\hline Participation Rate & 1.17 & 1.15 & 1.17 & 1.14 & 1.47 & 1.08 & 1.18 & 1.09 \\
\hline \multicolumn{9}{|c|}{ Panel B: Affirmative Action Policy (subsidy) } \\
\hline \multicolumn{9}{|l|}{ Welfare Measures } \\
\hline Men & 0.98 & 0.98 & 1.00 & 0.99 & 0.96 & 0.99 & 0.99 & 0.98 \\
\hline Women & 0.97 & 0.74 & 0.74 & 0.78 & 1.00 & 0.90 & 0.81 & 0.97 \\
\hline Total & 0.98 & 0.85 & 0.85 & 0.87 & 0.98 & 0.93 & 0.90 & 0.97 \\
\hline \multicolumn{9}{|c|}{ Labor Market Variables (Men/Women) } \\
\hline Reservation Wage & 0.90 & 0.96 & 1.23 & 1.09 & 0.83 & 0.94 & 1.09 & 1.09 \\
\hline Average Wage & 1.03 & 1.34 & 1.13 & 1.24 & 1.01 & 1.12 & 1.10 & 1.01 \\
\hline Unemployment Dura & 0.45 & 0.98 & 0.98 & 0.90 & 1.04 & 0.52 & 1.05 & 0.95 \\
\hline Unemployment Rate & 0.90 & 0.90 & 0.65 & 0.68 & 1.14 & 1.04 & 0.59 & 0.98 \\
\hline Participation Rate & 1.13 & 1.10 & 1.17 & 1.13 & 1.30 & 1.07 & 1.15 & 1.06 \\
\hline \multicolumn{9}{|c|}{ Panel C: Equal Pay Policy } \\
\hline \multicolumn{9}{|l|}{ Welfare Measures } \\
\hline Men & 0.95 & 0.95 & 0.98 & 0.97 & 0.91 & 0.96 & 0.96 & 0.92 \\
\hline Women & 1.01 & 0.75 & 0.76 & 0.80 & 1.02 & 0.91 & 0.86 & 1.00 \\
\hline Total & 0.97 & 0.84 & 0.85 & 0.87 & 0.97 & 0.93 & 0.91 & 0.97 \\
\hline \multicolumn{9}{|c|}{ Labor Market Variables (Men/Women) } \\
\hline Reservation Wage & 0.72 & 0.76 & 1.15 & 0.98 & 0.58 & 0.84 & 0.92 & 0.82 \\
\hline Average Wage & 0.97 & 1.29 & 1.10 & 1.19 & 0.94 & 1.08 & 1.04 & 0.92 \\
\hline Unemployment Dura & 0.47 & 1.03 & 0.99 & 0.91 & 1.14 & 0.53 & 1.07 & 0.99 \\
\hline Unemployment Rate & 0.94 & 0.95 & 0.66 & 0.69 & 1.24 & 1.07 & 0.60 & 1.01 \\
\hline Participation Rate & 1.07 & 1.05 & 1.14 & 1.11 & 1.19 & 1.06 & 1.11 & 1.02 \\
\hline
\end{tabular}

